Article

\title{
Multi-Mycotoxin Occurrence and Exposure Assessment Approach in Foodstuffs from Algeria
}

\author{
Choukri Khelifa Mahdjoubi ${ }^{1,2}\left(\mathbb{0}\right.$, Natalia Arroyo-Manzanares ${ }^{3}$, Nisserine Hamini-Kadar ${ }^{2}(\mathbb{D}$, \\ Ana M. García-Campaña ${ }^{1}$, Kihel Mebrouk ${ }^{2}$ and Laura Gámiz-Gracia ${ }^{1, *(1)}$ \\ 1 Department of Analytical Chemistry, Faculty of Sciences, University of Granada, 18071 Granada, Spain; \\ choukri_khelifa@hotmail.com (C.K.M.); amgarcia@ugr.es (A.M.G.-C.) \\ 2 Department of Biology, Faculty of Natural and Life Science, University of Oran 1, 31100 Oran, Algeria; \\ hamini.kadar@yahoo.fr (N.H.-K.); kihalm@gmail.com (K.M.) \\ 3 Department of Analytical Chemistry, Faculty of Chemistry, University of Murcia, 30003 Murcia, Spain; \\ natalia.arroyo@um.es \\ * Correspondence: lgamiz@ugr.es; Tel.: +34-9-5824-8594
}

Received: 9 February 2020; Accepted: 17 March 2020; Published: 19 March 2020

check for updates

\begin{abstract}
A survey on 120 cereal samples (barley, maize, rice and wheat) from Algerian markets has been carried out to evaluate the presence of 15 mycotoxins (ochratoxin A, deoxynivalenol, fumonisin $\mathrm{B} 1$ and B2, T-2 and HT-2 toxins, zearalenone, fusarenon X, citrinin, sterigmatocystin, enniatins A, $\mathrm{A} 1, \mathrm{~B}$ and B1, and beauvericin). With this purpose, a QuEChERS-based extraction and ultra-high performance liquid chromatography coupled to tandem mass spectrometry (UHPLC-MS/MS) were used. Analytical results showed that 78 cereal samples (65\%) were contaminated with at least one toxin, while $50 \%$ were contaminated with three to nine mycotoxins. T-2 toxin, citrinin, beauvericin and deoxynivalenol were the most commonly found mycotoxins (frequency of 50\%, 41.6\%, $40.8 \%$ and $33.3 \%$, respectively). Fumonisins (B1 + B2), enniatins B and B1, deoxynivalenol and zearalenone registered high concentrations (289-48878 $\mu \mathrm{g} / \mathrm{kg}, 1.2-5288 \mu \mathrm{g} / \mathrm{kg}, 15-4569 \mu \mathrm{g} / \mathrm{kg}, 48-2055 \mu \mathrm{g} / \mathrm{kg}$ and $10.4-579 \mu \mathrm{g} / \mathrm{kg}$, respectively). Furthermore, concentrations higher than those allowed by the European Union (EU) were observed in 21, 8 and 1 samples for fumonisins, zearalenone and deoxinivalenol, respectively. As a conclusion, the high levels of fumonisins (B1 + B2) in maize and deoxynivalenol, zearalenone and HT-2 + T-2 toxins in wheat, represent a health risk for the average adult consumer in Algeria. These results pointed out the necessity of a consistent control and the definition of maximum allowed levels for mycotoxins in Algerian foodstuffs.
\end{abstract}

Keywords: Mycotoxins; cereals; UHPLC-MS/MS; exposure assessment; Algeria

Key Contribution: The study describes the incidence of 15 mycotoxins in 120 Algerian cereal samples (barley, maize, rice and wheat grains) by UHPLC-MS/MS. The results have pointed out the high co-occurrence of mycotoxins, as well as the high concentration (above the maximum allowed concentration) of some mycotoxins legislated in the EU in those cereals, posing a risk for consumers. These results highlight the necessity of establishing maximum levels for mycotoxins in Algeria.

\section{Introduction}

Mycotoxins are secondary metabolites of low molecular weight produced by a variety of fungi (mainly Aspergillus, Fusarium and Penicillium spp.). They present diverse chemical structures, having different biological effects on animals and humans, such as teratogenicity, carcinogenicity, mutagenicity, immunotoxicity or neurotoxicity [1,2]. These toxic compounds are often naturally occurring in the food chain and, therefore, result in human exposure either by direct consumption of contaminated 
crops, plants, seeds and fruits, or indirectly through ingestion of food derived from exposed animals (meat, eggs or milk) [3-5].

More than 400 mycotoxins have been reported so far, being aflatoxins (AFs), trichothecenes, fumonisins, zearalenone (ZEN) and ochratoxin A (OTA) the most representatives. However, other mycotoxins are becoming a global issue of high concern due to their extensive incidence in food and feed, including emerging Fusarium toxins, such as beauvericin (BEA) and enniatins (ENNs) [6-8].

Humans and animals are more frequently exposed to multiple mycotoxins than to a single one [9-11], producing an increasing concern about the health hazard. The combined effects of mycotoxins have been reported in several studies [12-15]. However, the actual health risk assessment is limited to their single effects, since there is not enough information available about the nature of the observed effects or the relative potencies of each mycotoxin in the mixture [16].

Due to the toxic effects of these compounds, the EU $[17,18]$ and many countries have set maximum levels or recommendations in foodstuffs intended to human consumption (see Table 1). Moreover, for the most well-documented toxins, tolerable daily intakes (TDI) or provisional maximum tolerable daily intakes (PMTDI) have been established by the Food and Agriculture Organization (FAO)/World Health Organization (WHO) Joint Expert Committee on Food Additives (JECFA) [19,20].

Table 1. Maximum tolerable levels set for some mycotoxins in cereals.

\begin{tabular}{|c|c|c|}
\hline Mycotoxin & Commodity & Maximum Level $(\mu \mathrm{g} / \mathrm{kg})$ \\
\hline \multicolumn{3}{|c|}{ European Union $[17,18]$} \\
\hline Aflatoxin B1 & Cereals and cereal products & 2 \\
\hline \multirow{2}{*}{ Aflatoxins ${ }^{a}$} & Cereals and cereal products & 4 \\
\hline & Maize & 10 \\
\hline \multirow{2}{*}{ Zearalenone } & Unprocessed maize & 350 \\
\hline & Unprocessed cereals other than maize & 100 \\
\hline Fumonisins B1 + B2 & Unprocessed maize & 4000 \\
\hline Deoxynivalenol & Unprocessed cereals other than durum wheat, oats, maize & 1250 \\
\hline \multirow[t]{2}{*}{$\mathrm{T}-2+\mathrm{HT}-2$} & Unprocessed oats & 1000 \\
\hline & Unprocessed wheat, rye and other cereals & 100 \\
\hline \multicolumn{3}{|c|}{ United States of Americ [21,22] } \\
\hline Aflatoxin B1 & All food crops & 15 \\
\hline Fumonisins B1 + B2 + B3 & Unprocessed maize & 4000 \\
\hline \multicolumn{3}{|c|}{ Canada [23] } \\
\hline Deoxynivalenol & Unprocessed wheat & 2000 \\
\hline \multicolumn{3}{|c|}{ Japan $[24,25]$} \\
\hline \multicolumn{3}{|c|}{ China [26] } \\
\hline Aflatoxin B1 & Unprocessed wheat barley, other cereals & 5 \\
\hline Deoxynivalenol & Maize, barley, wheat, other cereals & 1000 \\
\hline Ochratoxin A & Unprocessed cereals & 5 \\
\hline Zearalenone & Unprocessed wheat and maize & 60 \\
\hline
\end{tabular}


Table 1. Cont.

\begin{tabular}{ccc}
\hline Mycotoxin & Commodity & Maximum Level $(\mu \mathrm{g} / \mathbf{k g})$ \\
\hline & Morocco [27] & \\
\hline Aflatoxin B1 & Cereals and cereal products & 2 \\
\hline Aflatoxins ${ }^{\text {a }}$ & Cereals and cereal products & 4 \\
\hline Ochratoxin A & Unprocessed cereals & 5 \\
\hline Deoxynivalenol & Unprocessed durum wheat, oats and maize & 1750 \\
\hline Zearalenone & Unprocessed maize & 200 \\
\hline & a AFs: Sum of AFB1 + AFB2 + AFG1 + AFG2; ${ }^{\text {b Provisional maximum level. }}$ \\
\hline
\end{tabular}

Studies show that mycotoxins are ubiquitous contaminants [28,29]. It is estimated that they are present in approximately $25 \%$ of cereals consumed worldwide and a recent study suggests that this percentage could be even higher [30]. In general, mycotoxin contamination is higher when climatic conditions are favourable. Algeria is a North African country whose climate is characterised by high temperatures and high relative humidity in some areas that seems to stimulate the toxigenic moulds growth and toxinogenesis, in which cereals and cereal-based products represent a staple food for the population [31]. Moreover, no applicable norms concerning mycotoxin contamination of cereal (local or imported) have been set in Algeria. Indeed, a large amount of cereal commercialized in Algeria is imported and little is known about toxin contamination. Therefore, in order to the health risks associated with mycotoxin exposure different preventive approaches have been used. These include enforcement of legislation, good agricultural practices and the monitoring of mycotoxin contamination. But for this, it is essential to establish evidence and data on the presence of mycotoxins and exposure levels. Accurate exposure data on mycotoxins is an important input in risk assessment and management efforts as well as in the establishment of appropriated legislation for the monitoring and control of mycotoxin exposure in food [32].

In order to quantify the concentration of these hazards in different commodities, reliable and accurate analytical methods that allow their unambiguous identification and accurate quantification at low concentration are needed. In this sense, liquid chromatography (LC) or ultra-high performance LC (UHPLC) coupled to tandem mass spectrometry (MS/MS) have become the techniques of choice for the determination of multiple mycotoxins in food and feed [33-35]. In addition, alternative sample treatment methods, such as QuEChERS (acronym of Quick, Easy, Cheap, Effective, Rugged and Safe), are being increasingly applied to the analysis of mycotoxins, due to their feasibility, flexibility, versatility, low cost and rapidity [36].

Within this context, the main objective of this work is the validation of an analytical method based on a simple QuEChERS-based extraction and UHPLC-MS/MS for the determination of 15 mycotoxins, namely: OTA, deoxynivalenol (DON), fumonisin B1 (FB1) and B2 (FB2), T-2 and HT-2 toxins, ZEN, fusarenon X (F-X), citrinin (CIT), sterigmatocystin (STE), enniatin A (ENNA), A1 (ENNA1), B (ENNB) and B1 (ENNB1) and BEA. Secondly, the analysis of cereals samples (barley, maize, rice and wheat) collected from different Algerian markets will help to estimate the potential contribution to the dietary exposure of Algerian consumers.

\section{Results}

\subsection{Method Validation}

The selected analytical method was validated for each cereal in terms of linearity, matrix effect, recovery, precision, limits of detection (LODs) and limits of quantification (LOQs). The results are summarised in the supplementary material (Table S1).

Method linearity was assessed by spiking blank samples at five concentration levels (processed in duplicate). All calibration curves showed a good linearity, with coefficients $\left(R^{2}\right)$ higher than 0.98 in all the cases. LODs and LOQs were determined as the concentration of analyte giving a signal to noise 
ratio (S/N) equal to 3 and 10, respectively. In all cases, LOQs were lower than maximum permitted or recommended concentrations established by the EU for those mycotoxins in cereals (FBs, DON, OTA, ZEN, T-2 and HT-2 toxin) [17,18].

Matrix effect was evaluated at the following concentration levels: OTA and STE: $25 \mu \mathrm{g} / \mathrm{kg}$; CIT: $100 \mu \mathrm{g} / \mathrm{kg}$; FB1, FB2, T-2, HT-2 and ZEN: $250 \mu \mathrm{g} / \mathrm{kg}$; ENNB, ENNB1, ENNA, ENNA1 and BEA: $400 \mu \mathrm{g} / \mathrm{kg}$; DON: $1000 \mu \mathrm{g} / \mathrm{kg}$ and F-X: $2500 \mu \mathrm{g} / \mathrm{kg}$. Matrix effect was calculated as follow:

$\mathrm{ME}=100 \times($ signal of spiked extract - signal of standard solution)/signal of standard solution

A strong ion suppression was observed for all the selected compounds in the four matrices under study, ranging from $-77.8 \%$ to $-18.2 \%$ for barley, $-76.5 \%$ to $-15.6 \%$ for maize, $-80.4 \%$ to $-18.2 \%$ for rice and $-76.9 \%$ to $-14.3 \%$ for wheat (see supplementary material, Figure S1). As a consequence, calibration curves in matrix were used.

The efficiency of the extraction process was evaluated by recovery studies, spiking blank samples at the same levels used in the matrix effect study. Each sample was processed in triplicate and injected three times. The ratio of peak areas of the samples spiked before extraction and the extracts spiked after extraction was used to calculate the recovery. The average recovery values were: $87.5 \%$ for barley, $84.8 \%$ for maize, $88.5 \%$ for rice and $86.2 \%$ for wheat.

Intra-day (repeatability) and inter-day precision (intermediate precision) were evaluated and expressed as relative standard deviation (\%RSD). Spiked blank samples (processed and injected three times) at the same concentration levels mentioned above for the matrix effect and recovery studies were used. For the intra-day precision study, samples were analysed on the same day, while the inter-day precision was estimated through samples analysed on three consecutive days. The relative standard deviation (\%RSD) for intra-day and inter-day precision were lower than $14 \%$ and $23 \%$, respectively, for all the mycotoxins and matrix combination (see supplementary material Table S2). These values were all in a permitted range by European Commission [37].

\subsection{Mycotoxins Occurrence Data}

A total of 120 samples comprising barley $(n=30)$, maize $(n=30)$, rice $(n=30)$ and wheat $(n=30)$ were evaluated for the occurrence of mycotoxins (OTA, DON, FB1, FB2, T-2, HT-2, ZEN, F-X, CIT, STE, ENNA, ENNA1, ENNB, ENNB1 and BEA). Table 2 presents the occurrence, concentration range and mean concentration of each mycotoxin in positive cereal samples that is, considering only mycotoxins with a concentration above the LOQ.

Moreover, 78 out of 120 samples (65\%) evidenced at least one mycotoxin above the LOQ, and 13 out of 15 mycotoxins included in the study were found in some of the analysed samples, being the exceptions OTA and STE (not detected). Overall, T-2, CIT, BEA and DON were the most commonly found mycotoxins with a global incidence of $50 \%, 40.8 \%, 38.3 \%$ and $33.3 \%$, respectively. However, the maximum concentration value was found for FB1 in maize $(42,143 \mu \mathrm{g} / \mathrm{kg})$.

The results obtained for each mycotoxin (or group of mycotoxins) are commented below.

\subsubsection{Occurrence of Trichothecenes}

Regarding the distribution of the studied trichothecenes (HT-2, T-2, DON and F-X), T-2 was the most frequently found, being present in 100\% samples of maize and wheat at concentrations ranging from 16.6 to $47.2 \mu \mathrm{g} / \mathrm{kg}$, being the mean concentrations (considering only positive samples) $24.9 \mu \mathrm{g} / \mathrm{kg}$ in maize and $21.8 \mu \mathrm{g} / \mathrm{kg}$ in wheat. HT-2 was present only in 7 wheat samples (23\%) at concentrations from 8.4 to 36.7 $\mu \mathrm{g} / \mathrm{kg}$ (mean value $18.1 \mu \mathrm{g} / \mathrm{kg}$ ). None of the samples exceeded the maximum recommended concentration for these toxins in non-processed cereals (ranging from 100-1000 $\mu \mathrm{g} / \mathrm{kg}$ for the sum of T-2 + HT-2) [17].

DON was found in 27 wheat samples $(90 \%)$ and 13 maize samples $(43.3 \%)$, with mean concentrations of positives samples of $588 \mu \mathrm{g} / \mathrm{kg}$ and $632 \mu \mathrm{g} / \mathrm{kg}$, respectively. The highest concentration found for DON was $2055 \mu \mathrm{g} / \mathrm{kg}$, corresponding to one maize sample that exceeded the maximum permitted concentration for DON established by the EU in maize $(1750 \mu \mathrm{g} / \mathrm{kg})$ [18]. As an example, a chromatogram of a wheat sample contaminated with DON is shown in supplementary material (Figure S2A). 
Table 2. Summary of mycotoxins found in the analysed cereal samples.

\begin{tabular}{|c|c|c|c|c|c|c|c|c|c|c|c|c|c|c|c|c|}
\hline & \multicolumn{4}{|c|}{ Barley $(n=30)$} & \multicolumn{4}{|c|}{ Maize $(n=30)$} & \multicolumn{4}{|c|}{ Rice $(n=30)$} & \multicolumn{4}{|c|}{ Wheat $(n=30)$} \\
\hline & $I(\%)^{a}$ & Mean $^{b}$ & LOD-LOQ $^{c}$ & Range $^{d}$ & $I(\%)^{a}$ & Mean $^{b}$ & LOD-LOQ $^{c}$ & Range $^{d}$ & $I(\%)^{a}$ & Mean $^{b}$ & LOD-LOQ $^{c}$ & Range $^{\mathrm{d}}$ & $I(\%)^{a}$ & Mean $^{b}$ & LOD-LOQ $^{c}$ & Range $^{d}$ \\
\hline Analytes & & $(\mu \mathrm{g} / \mathrm{kg})$ & & & & $(\mu \mathrm{g} / \mathrm{kg})$ & & & & $(\mu \mathrm{g} / \mathrm{kg})$ & & & & $(\mu \mathrm{g} / \mathrm{kg})$ & & \\
\hline FB1 & nd & nd & - & - & $29(96.6)$ & 14,812 & & $289-42,143$ & nd & nd & - & - & nd & nd & - & - \\
\hline FB2 & nd & nd & - & - & $27(90)$ & 2789 & - & $27.5-8603$ & nd & nd & - & - & nd & nd & - & - \\
\hline HT-2 & nd & nd & 9 & - & nd & nd & - & - & nd & nd & - & - & $7(23)$ & 18.1 & 3 & $8.4-36.7$ \\
\hline $\mathrm{T}-2$ & nd & nd & - & - & $30(100)$ & 24.9 & - & $24.6-25.7$ & nd & nd & - & - & $30(100)$ & 21.8 & - & $16.6-47.2$ \\
\hline DON & nd & nd & - & - & $13(43)$ & 632 & - & $47.6-2055$ & nd & nd & - & - & $27(90)$ & 588 & 1 & $68.3-1363$ \\
\hline ZEN & nd & nd & 2 & - & $7(23.3)$ & 109 & - & $20.4-579$ & $6(20)$ & 9.9 & 17 & $8.6-15.5$ & $19(63.3)$ & 102 & 9 & $9.6-295$ \\
\hline $\mathrm{F}-\mathrm{X}$ & $3(10)$ & 190 & 2 & $142-284$ & $24(80)$ & 281 & 1 & $177-477$ & nd & nd & - & - & $3(10)$ & 152 & 7 & $139-159$ \\
\hline OTA & nd & nd & - & - & nd & nd & - & - & nd & nd & - & - & nd & nd & - & - \\
\hline CIT & $9(30)$ & 26.2 & 2 & $10.9-52.0$ & $25(83.3)$ & 32.7 & - & $8.6-273$ & nd & nd & 23 & - & $15(50)$ & 16.8 & 14 & $9.8-32.3$ \\
\hline STE & nd & nd & - & - & nd & nd & - & - & nd & nd & - & - & nd & nd & - & - \\
\hline BEA & nd & nd & - & - & $25(83.3)$ & 3.8 & 4 & $0.85-31.4$ & nd & nd & - & - & $21(70)$ & 155.4 & - & $2.8-486$ \\
\hline ENNA & nd & nd & - & - & nd & nd & - & - & nd & nd & - & - & $7(23.3)$ & 28.3 & - & $8.4-87.6$ \\
\hline ENNA1 & nd & nd & - & - & $3(10)$ & 56.4 & - & $11.5-103$ & nd & nd & - & - & $14(46.7)$ & 107 & 3 & $4.0-395$ \\
\hline ENNB & nd & nd & - & - & nd & nd & - & - & nd & nd & - & - & $18(60)$ & 1668 & - & $1.2-5288$ \\
\hline ENNB1 & nd & nd & - & - & $2(6)$ & 60.9 & - & $15.0-107$ & nd & nd & - & - & $21(70)$ & 469 & - & $19.5-4569$ \\
\hline Total & $12(40)$ & & & & $30(100)$ & & & & $6(20)$ & & & & $30(100)$ & & & \\
\hline
\end{tabular}

${ }^{\mathrm{a}}$ Incidence of samples $\geq$ LOQ (\% of samples $\geq$ LOQ), ${ }^{\mathrm{b}}$ Mean value for samples $\geq \mathrm{LOQ},{ }^{\mathrm{c}}$ Number of samples $\geq$ LOD and $\leq \mathrm{LOQ},{ }^{\mathrm{d}}$ minimum value- $\mathrm{maximum}$ value, $n$ : Number of samples; nd: Not detected. 
F-X was determined in 3 samples of barley (10\%), 24 of maize $(80 \%)$ and 3 of wheat $(10 \%)$. The maximum content of F-X was found in a maize sample $(477 \mu \mathrm{g} / \mathrm{kg})$.

In addition, the incidence of T-2 toxin in positive samples was higher than the incidence of DON in the same samples. Similar to our finding, Bouafifssa et al. [38] reported higher levels of T-2 and HT-2 compared to DON in Moroccan pasta, with contamination levels from 4 to $419 \mu \mathrm{g} / \mathrm{kg}$ and 4 to $50 \mu \mathrm{g} / \mathrm{kg}$ for T-2 and HT-2, respectively. The higher incidence of DON in maize and wheat compared to other cereals was also reported by Pleadin et al. [39] in 181 cereal samples from Croatia, where DON was found in $71 \%, 65 \%, 53 \%$ and $21 \%$ samples of maize, wheat, barley and oat, with mean concentrations of $1565,223,342$ and $145 \mu \mathrm{g} / \mathrm{kg}$, respectively. However, lower incidence and concentrations of DON, HT-2, T-2 and F-X were found in cereal samples from Italy, where mean levels in positive samples were 20.1, 4.8, 0.3 and $36.7 \mu \mathrm{g} / \mathrm{kg}$, for DON, HT-2, T-2 and F-X respectively [40].

\subsubsection{Occurrence of Zearalenone}

ZEN was found in 7 samples of maize (23.3\%), 6 of rice (20\%) and 19 of wheat $(63.3 \%)$, being the mean concentrations of positive samples $109 \mu \mathrm{g} / \mathrm{kg}$ in maize, $9.9 \mu \mathrm{g} / \mathrm{kg}$ in rice and $102 \mu \mathrm{g} / \mathrm{kg}$ in wheat. One sample of maize $(579 \mu \mathrm{g} / \mathrm{kg}$ ) and 7 samples of wheat (with concentrations up to $295 \mu \mathrm{g} / \mathrm{kg}$ ) exceeded the maximum permitted levels established in the EU for ZEN (350 $\mu \mathrm{g} / \mathrm{kg}$ for maize and $100 \mu \mathrm{g} / \mathrm{kg}$ for other unprocessed cereals) [18].

The incidence of ZEN in our study was similar to those reported in other studies [41,42], but the contamination levels were lower than other values from literature. For instance, ZEN was found at concentrations up to $1399 \mu \mathrm{g} / \mathrm{kg}$ in cereals from Nigeria [43] and up to $15,700 \mu \mathrm{g} / \mathrm{kg}$ in maize samples from Belgium, where mean level of ZEN in the analysed samples was $2180 \mu \mathrm{g} / \mathrm{kg}$ [44]. However, other studies reported lower ZEN concentrations with an average of 12 and $14 \mu \mathrm{g} / \mathrm{kg}$ in Italian and Moroccan cereals, respectively $[40,45]$.

\subsubsection{Occurrence of Fumonisins}

FB1 and FB2 were found only in maize samples, with high concentrations and incidence rate. Thus, FB1 was present in 29 samples (96.6\%) at concentrations from 289 up to $42,143 \mu \mathrm{g} / \mathrm{kg}$, whereas FB2 was quantified in 27 samples $(90 \%)$ at concentrations from 27.5 to $8603 \mu \mathrm{g} / \mathrm{kg}$. The mean concentrations for positives samples were 14,812 and $2789 \mu \mathrm{g} / \mathrm{kg}$ for FB1 and FB2, respectively. Considering the sum of fumonisins (FB1 + FB2), it was in the range of $289-48,878 \mu \mathrm{g} / \mathrm{kg}$. A total of 21 samples $(70 \%)$ showed concentrations of (FB1 + FB2) above the maximum allowed level established by the EU $(4000 \mu \mathrm{g} / \mathrm{kg}$ for unprocessed maize) [18] suggesting the high exposure of the population to these toxins.

According to the analyses, fumonisins were not detected in barley, rice and wheat samples. Such a trend was also observed by Ghali et al. in cereals from Tunisia, reporting the highest levels for fumonisins in maize samples at an incidence rate of $52 \%$ [46]. This confirms that the risk of fumonisin contamination of wheat, barley and rice is rather low due to the known tendency of the Fusarium spp. producing fumonisins (F. verticillioides and F. proliferatum) to infect maize [47]. This result is in agreement with other previous studies: thus, a high fumonisin incidence was reported in Nigerian maize-based products with concentrations ranging from 74 to $22064 \mu \mathrm{g} / \mathrm{kg}$ [43], in maize from South Africa, reporting concentrations up to $53863 \mu \mathrm{g} / \mathrm{kg}$ for FB1 [48], and from Ethiopia, where $77 \%$ samples of maize contaminated with fumonisins at concentrations between $25-4500 \mu \mathrm{g} / \mathrm{kg}$, were attributed to F. verticillioides [49].

\subsubsection{Occurrence of Citrinin}

Remarkably, $40.8 \%$ of the total analysed samples were contaminated by CIT; it was present in $9(30 \%), 25$ (83.3\%) and $15(50 \%)$ samples of barley, maize and wheat, respectively, showing mean levels of $26.2 \mu \mathrm{g} / \mathrm{kg}$ in barley, $32.7 \mu \mathrm{g} / \mathrm{kg}$ in maize and $16.8 \mu \mathrm{g} / \mathrm{kg}$ in wheat samples. The highest concentration of CIT was found in a maize sample $(273 \mu \mathrm{g} / \mathrm{kg})$. CIT was not detected in rice samples.

These results may be explained by the susceptibility of the analysed cereals (barley, maize and wheat) to CIT-producing fungi (Aspergillus and Penicillium spp.) and to the influence of climatic 
conditions such as substrate composition, temperature and water activity (aw) to enhance CIT production, especially during storage, as it is well-known that mycotoxin production is modulated by environmental factors [50].

\subsubsection{Occurrence of Emerging Mycotoxins}

Only maize and wheat samples were contaminated with BEA and ENNs, while these emerging mycotoxins were not detected in rice and barley. ENNB1 was the most frequent ENN (2 samples (6.6\%) of maize and in 21 samples (70\%) of wheat) with concentrations from 15.0-107 $\mu \mathrm{g} / \mathrm{kg}$ and 19.5-4569 $\mu \mathrm{g} / \mathrm{kg}$ for maize and wheat, respectively. ENNA1 was quantified in 3 samples (10\%) of maize and 14 samples (46.7) of wheat, with mean concentrations for positive samples of $56.4 \mu \mathrm{g} / \mathrm{kg}$ and $107 \mu \mathrm{g} / \mathrm{kg}$, respectively. ENNA and ENNB were found in 7 (23.3\%) and 18 samples (60\%) of wheat, respectively. The contamination levels varied between 8.4 and $87.6 \mu \mathrm{g} / \mathrm{kg}$ for ENNA and from 1.2 to $5288 \mu \mathrm{g} / \mathrm{kg}$ for ENNB, with mean values for positive samples of 28.3 and $1668 \mu \mathrm{g} / \mathrm{kg}$, respectively. ENNA and ENNB were not detected in maize. A chromatogram of a wheat sample contaminated with ENNB1 is shown in supplementary material (Figure S2B).

Concerning BEA, 25 samples (83.3\%) of maize and 21 samples (70\%) of wheat were positives, with concentrations between $0.85-31.4 \mu \mathrm{g} / \mathrm{kg}$ and $2.8-486 \mu \mathrm{g} / \mathrm{kg}$ in maize and wheat samples, respectively.

Other previous works including determination of ENNs and BEA in cereals also showed the high incidence of these mycotoxins. Thus, a high incidence of BEA (80\%) was recently reported in Serbian maize with levels ranging from 8 to $129 \mu \mathrm{g} / \mathrm{kg}$ [7]. Moreover, a study on the occurrence of emerging mycotoxins in Spanish cereals showed high incidence of ENNs (73.4\%), wherein ENNA1 was the most frequent emerging mycotoxins, with the highest concentrations $(33.3-814 \mathrm{mg} / \mathrm{kg})$ [51]. Furthermore, the high contamination of BEA and ENNs was also reported in cereals from Italy [40] and up to $800 \mathrm{mg} / \mathrm{kg}$ of ENNB1 were found in a wheat-based cereal sample from Morocco [8]. In contrast with our results, Oueslati et al. [52] did not detect BEA in maize and wheat from Tunisia.

\subsubsection{Co-Occurrence of Mycotoxins in Analysed Samples}

The co-occurrence of mycotoxins as well as the main combinations found in the analysed cereal samples were evaluated (see supplementary material Table S3). Among the positive samples, 50\% (all maize $(n=30)$ and wheat $(n=30)$ samples) were found to be contaminated with more than one mycotoxin. The most frequent co-occurrence was the combination of 5 mycotoxins for maize and 8 mycotoxins for wheat. Moreover, different combinations were observed, depending on the cereal, the most frequent combinations being: $(\mathrm{FB} 1+\mathrm{FB} 2+\mathrm{T}-2+\mathrm{F}-\mathrm{X}+\mathrm{CIT}+\mathrm{BEA})$ and $(\mathrm{FB} 1+\mathrm{FB} 2+\mathrm{T}-2+\mathrm{F}-\mathrm{X}+$ BEA) in maize, and (DON + T-2 + ZEN + ENNA1 + ENNB + ENNB1) in wheat samples. The highest number of mycotoxins occurring simultaneously was nine in 2 maize samples (DON + FB1 + FB2 + $\mathrm{T}-2+\mathrm{ZEN}+\mathrm{F}-\mathrm{X}+\mathrm{CIT}+\mathrm{BEA}+\mathrm{ENNA} 1)$ and 1 wheat sample $(\mathrm{DON}+\mathrm{HT}-2+\mathrm{T}-2+\mathrm{ZEN}+\mathrm{CIT}+$ $\mathrm{BEA}+\mathrm{ENNA} 1+\mathrm{ENNB}+\mathrm{ENNB1})$.

The co-occurrence of mycotoxins in cereals has been studied previously, especially in the Mediterranean area [38,40,52]. In agreement with our results, in wheat grains from Morocco, 51\% samples were contaminated with 2-6 mycotoxins [53], whereas that at least one mycotoxin was present in the $65 \%$ cereal-derived samples from Spain [54]. Recently, a study performed in Italy showed that $81 \%$ cereal samples were contaminated with more than one mycotoxin and the most frequent co-occurrence was with DON, F-X, ENNB and ENNA1 [40]. A summary of the results obtained in this study and other previously reported occurrence studies are presented in Table 3. 
Table 3. Occurrence of mycotoxins in cereals from different surveys.

\begin{tabular}{|c|c|c|c|c|c|c|c|c|c|c|c|c|c|c|c|}
\hline & \multicolumn{3}{|c|}{ Barley $(n=30)$} & \multicolumn{3}{|c|}{ Maize $(n=30)$} & \multicolumn{3}{|c|}{ Rice $(n=30)$} & \multicolumn{3}{|c|}{ Wheat $(n=30)$} & \multirow[b]{2}{*}{ Analytical Method } & \multirow[b]{2}{*}{$\begin{array}{c}\mathrm{LOQ} \\
(\mu \mathrm{g} / \mathrm{kg})\end{array}$} & \multirow[b]{2}{*}{ Ref. } \\
\hline & $I(\%)^{\mathrm{a}}$ & $\begin{array}{l}\text { Range }{ }^{c} \\
(\mu \mathrm{g} / \mathrm{kg})\end{array}$ & $\begin{array}{l}\text { Mean b } \\
(\mu \mathrm{g} / \mathrm{kg})\end{array}$ & $\mathrm{I}(\%)^{\mathrm{a}}$ & $\begin{array}{l}\text { Range c } \\
(\mu \mathrm{g} / \mathrm{kg})\end{array}$ & $\begin{array}{l}\text { Mean }{ }^{b} \\
(\mu \mathrm{g} / \mathrm{kg})\end{array}$ & $I(\%)^{a}$ & $\begin{array}{l}\text { Range }^{\mathrm{c}} \\
(\mu \mathrm{\mu g} / \mathrm{kg})\end{array}$ & $\begin{array}{c}\text { Mean } \\
(\mu \mathrm{gg} / \mathrm{kg})\end{array}$ & I (\%) ${ }^{\mathrm{a}}$ & $\begin{array}{l}\text { Range }{ }^{c} \\
(\mu \mathrm{g} / \mathrm{kg})\end{array}$ & $\begin{array}{l}\text { Mean b } \\
(\mu \mathrm{g} / \mathrm{kg})\end{array}$ & & & \\
\hline FB1 & nd & - & nd & $29(96.6)$ & $289-42,143$ & 14812 & nd & - & nd & nd & - & nd & \multirow{15}{*}{$\begin{array}{l}\text { Ultra-high } \\
\text { performance liquid } \\
\text { chromatography } \\
\text { coupled to tandem } \\
\text { mass spectrometry } \\
\text { (UHPL-MS/MS) }\end{array}$} & $2.6-4.8$ & \multirow{15}{*}{ This work } \\
\hline FB2 & nd & - & nd & $27(90)$ & $27.5-8603$ & 2789 & nd & - & nd & nd & - & nd & & $2.2-10$ & \\
\hline HT-2 & nd & - & nd & nd & - & nd & nd & - & nd & $7(23)$ & $8.4-36.7$ & 18.1 & & $2.8-9.9$ & \\
\hline $\mathrm{T}-2$ & nd & - & nd & $30(100)$ & $24.6-25.7$ & 24.9 & nd & - & nd & $30(100)$ & $16.6-47.2$ & 21.8 & & $2.3-4.4$ & \\
\hline DON & nd & - & nd & $13(43)$ & $47.6-2055$ & 632 & nd & - & nd & $27(90)$ & $68.3-1363$ & 588 & & $4.2-4.8$ & \\
\hline ZEN & nd & - & nd & $7(23.3)$ & $20.4-579$ & 109 & $6(20)$ & $8.6-15.5$ & 9.9 & $19(63.3)$ & 9.6-295 & 102 & & $4.3-9.7$ & \\
\hline$F-X$ & $3(10)$ & $142-284$ & 190 & $24(80)$ & $177-477$ & 281 & nd & - & nd & $3(10)$ & 139-159 & 152 & & $90-174$ & \\
\hline OTA & nd & - & nd & nd & - & nd & nd & - & nd & nd & - & nd & & $20-92$ & \\
\hline CIT & $9(30)$ & $10.9-52.0$ & 26.2 & $25(83.3)$ & $8.6-273$ & 32.7 & nd & - & nd & $15(50)$ & $9.8-32.3$ & 16.8 & & $8.4-23$ & \\
\hline STE & nd & - & nd & nd & - & nd & nd & - & nd & nd & - & nd & & $0.6-1.3$ & \\
\hline BEA & nd & - & nd & $25(83.3)$ & $0.85-31.4$ & 3.8 & nd & - & nd & $21(70)$ & $2.8-486$ & 155.4 & & $0.6-1.3$ & \\
\hline ENNA & nd & - & nd & nd & - & nd & nd & - & nd & $7(23.3)$ & $8.4-87.6$ & 28.3 & & $0.5-1.2$ & \\
\hline ENNA1 & nd & - & nd & $3(10)$ & $11.5-103$ & 56.4 & nd & - & nd & $14(46.7)$ & $4.0-395$ & 107 & & $1.4-2.7$ & \\
\hline ENNB & nd & - & nd & nd & - & nd & nd & - & nd & $18(60)$ & $1.2-5288$ & 1668 & & $1.2-3.8$ & \\
\hline \multirow[t]{3}{*}{ ENNB1 } & nd & - & nd & $2(6)$ & $15.0-107$ & 60.9 & nd & - & nd & $21(70)$ & $19.5-4569$ & 469 & & $2.6-4.4$ & \\
\hline & \multicolumn{3}{|c|}{ Barley $(n=9)$} & \multicolumn{3}{|c|}{ Oat $(n=7)$} & \multicolumn{3}{|c|}{ Rye $(n=11)$} & \multicolumn{3}{|c|}{ Wheat $(n=57)$} & \multirow[b]{2}{*}{ Analytical Method } & \multirow[b]{2}{*}{$\underset{(\mu \mathrm{g} / \mathrm{kg})}{\mathrm{LOQ}}$} & \multirow[b]{2}{*}{ Ref. } \\
\hline & $\mathrm{I}(\%)^{\mathrm{a}}$ & $\begin{array}{l}\text { Range }{ }^{c} \\
(\mu \mathrm{g} / \mathrm{kg})\end{array}$ & $\begin{array}{l}\text { Mean b } \\
(\mu \mathrm{g} / \mathrm{kg})\end{array}$ & $\mathrm{I}(\%)^{\mathrm{a}}$ & $\begin{array}{l}\text { Range c } \\
(\mu \mathrm{g} / \mathrm{kg})\end{array}$ & $\begin{array}{l}\text { Mean }{ }^{b} \\
(\mu \mathrm{g} / \mathrm{kg})\end{array}$ & $I(\%)^{a}$ & $\begin{array}{l}\text { Range }{ }^{c} \\
(\mu \mathrm{g} / \mathrm{kg})\end{array}$ & $\begin{array}{c}\text { Mean } \\
(\mu \mathrm{gg} / \mathrm{kg})\end{array}$ & I (\%) ${ }^{\mathrm{a}}$ & $\begin{array}{l}\text { Range }{ }^{c} \\
(\mu \mathrm{g} / \mathrm{kg})\end{array}$ & $\begin{array}{l}\text { Mean b } \\
(\mu \mathrm{g} / \mathrm{kg})\end{array}$ & & & \\
\hline DON & $1(11)$ & up to 35.5 & & $4(57)$ & $10.3-83$ & 29.9 & $5(45.5)$ & $16.5-79.6$ & 23.23 & $16(28)$ & $9.6-99.6$ & 10.96 & \multirow{15}{*}{$\begin{array}{c}\text { LC- } \\
\text { MS/MS }\end{array}$} & 10 & \multirow{15}{*}[40]{} \\
\hline 3-AcDON & nd & - & nd & $1(14.2)$ & 5.23 & 5.24 & nd & - & nd & nd & - & nd & & 15 & \\
\hline 15-AcDON & nd & - & nd & nd & - & nd & nd & - & nd & $2(3.5)$ & $10.8-29.13$ & 0.64 & & 15 & \\
\hline FUS- $\mathrm{x}$ & $4(44)$ & $27.5-47.3$ & 18.43 & $3(42.8)$ & $26-75$ & 23 & $5(45.5)$ & $42.4-70.2$ & 28.52 & $14(24)$ & $12.50-102$ & 18.44 & & 15 & \\
\hline NIV & $3(33)$ & 21.7-106 & 25.15 & $4(57)$ & $45.5-50.4$ & 27.13 & $2(18)$ & $33.9-34.4$ & 56.9 & $11(19)$ & $12-106$ & 8.86 & & 15 & \\
\hline DAS & nd & - & nd & nd & - & nd & nd & - & nd & nd & - & nd & & 10 & \\
\hline NEO & nd & - & nd & nd & - & nd & nd & - & nd & nd & - & nd & & 5 & \\
\hline HT-2 & nd & - & nd & nd & - & nd & $3(27.2)$ & $6.98-50.3$ & 5.34 & $3(5.2)$ & $6.78-60.10$ & 4.44 & & 10 & \\
\hline $\mathrm{T}-2$ & nd & - & nd & nd & - & nd & nd & - & nd & $2(3.5)$ & 7.14-17.8 & 0.39 & & 5 & \\
\hline ZEN & $2(22)$ & 11.15 & 11.16 & nd & - & nd & nd & - & nd & $5(8.7)$ & $2.35-27.15$ & 12.17 & & 5 & \\
\hline$\alpha-$ ZEN & nd & - & nd & nd & - & nd & nd & - & nd & nd & - & nd & & 5 & \\
\hline$\beta$-ZEN & nd & - & nd & nd & - & nd & nd & - & nd & nd & - & nd & & 5 & \\
\hline BEA & nd & - & nd & $4(57)$ & $7.2-41$ & 8.8 & $5(45.5)$ & $8.9-16.5$ & 2.72 & $5(8.7)$ & $9.6-35$ & 12.8 & & 15 & \\
\hline ENNB & nd & - & nd & $3(42.8)$ & $5.5-97$ & 2.8 & $6(54.4)$ & $6.7-45$ & 5.8 & $16(28)$ & $5.5-97$ & 20.2 & & 15 & \\
\hline ENNB1 & $2(22)$ & $5.5-7.3$ & 1.4 & nd & - & nd & nd & - & nd & $2(3.5)$ & $5.47-33.1$ & 0.43 & & 15 & \\
\hline
\end{tabular}


Table 3. Cont

\begin{tabular}{|c|c|c|c|c|c|c|c|c|c|c|c|c|c|c|c|}
\hline & \multicolumn{3}{|c|}{ Barley $(n=9)$} & \multicolumn{3}{|c|}{ Oat $(n=7)$} & \multicolumn{3}{|c|}{ Rye $(n=11)$} & \multicolumn{3}{|c|}{ Wheat $(n=57)$} & \multirow[b]{2}{*}{ Analytical Method } & \multirow[b]{2}{*}{$\begin{array}{c}\mathrm{LOQ} \\
(\mu \mathrm{g} / \mathrm{kg})\end{array}$} & \multirow[b]{2}{*}{ Ref. } \\
\hline & $I(\%)^{a}$ & $\begin{array}{l}\text { Range } \\
(\mu \mathrm{g} / \mathrm{kg})\end{array}$ & $\begin{array}{l}\text { Mean }{ }^{b} \\
(\mu \mathrm{g} / \mathrm{kg})\end{array}$ & $I(\%)^{a}$ & $\begin{array}{l}\text { Range }^{c} \\
(\mu \mathrm{g} / \mathrm{kg})\end{array}$ & $\begin{array}{l}\text { Mean b } \\
(\mu \mathrm{g} / \mathrm{kg})\end{array}$ & $I(\%)^{a}$ & $\begin{array}{l}\text { Range } \\
(\mu \mathrm{g} / \mathrm{kg})\end{array}$ & $\begin{array}{c}\text { Mean } \\
(\mu \mathrm{g} / \mathrm{kg})\end{array}$ & $I(\%)^{a}$ & $\begin{array}{l}\text { Range }^{c} \\
(\mu \mathrm{g} / \mathrm{kg})\end{array}$ & $\begin{array}{l}\text { Mean }{ }^{\mathrm{b}} \\
(\mu \mathrm{g} / \mathrm{kg})\end{array}$ & & & \\
\hline ENNB4 & $8(88.9)$ & $6.6-60$ & 15.7 & $4(57)$ & $20-284.2$ & 50.7 & $4(36.3)$ & $23.4-74$ & 13.8 & $18(31)$ & $5.7-110.2$ & 38.44 & & 15 & \\
\hline ENNA & nd & - & nd & nd & - & nd & $4(36.3)$ & $7.8-9.8$ & 7.1 & $6(10)$ & $8.4-29.8$ & 1.56 & & 10 & \\
\hline \multirow[t]{3}{*}{ ENNA1 } & nd & - & nd & $2(28.5)$ & $9-45.5$ & 8.7 & nd & - & nd & $11(19)$ & $5.3-55$ & 0.74 & & 15 & \\
\hline & \multicolumn{3}{|c|}{ Barley $(n=5)$} & \multicolumn{3}{|c|}{ Sorghum $(n=3)$} & \multicolumn{3}{|c|}{ Processed cereals $(n=13)$} & \multicolumn{3}{|c|}{ Wheat $(n=34)$} & \multirow{2}{*}{ Analytical Method } & \multirow{2}{*}{$\underset{(\mu \mathrm{g} / \mathrm{kg})}{\mathrm{LOQ}}$} & \multirow[b]{2}{*}{ Ref. } \\
\hline & $\mathrm{I}(\%)^{\mathrm{a}}$ & $\begin{array}{l}\text { Range c } \\
(\mu \mathrm{g} / \mathrm{kg})\end{array}$ & $\begin{array}{l}\text { Mean b } \\
(\mu / / k g)\end{array}$ & I (\%) a & $\begin{array}{l}\text { Range c } \\
(\mu \mathrm{g} / \mathrm{kg})\end{array}$ & $\begin{array}{l}\text { Mean b } \\
(\mu \mathrm{g} / \mathrm{kg})\end{array}$ & $I(\%)^{a}$ & $\begin{array}{l}\text { Range }{ }^{c} \\
(\mu \mathrm{g} / \mathrm{kg})\end{array}$ & $\begin{array}{c}\text { Mean } \\
(\mu \mathrm{g} / \mathrm{kg})\end{array}$ & $I(\%)^{a}$ & $\begin{array}{l}\text { Range } e^{c} \\
(\mu \mathrm{g} / \mathrm{kg})\end{array}$ & $\begin{array}{l}\text { Mean b } \\
(\mu \mathrm{\mu g} / \mathrm{kg})\end{array}$ & & & \\
\hline AFB1 & nd & - & nd & 66.6 & $14.4-79.9$ & 46.7 & nd & - & nd & nd & - & nd & \multirow{6}{*}{ UHPLC-MS/MS } & 1 & \multirow{6}{*}{ [52] } \\
\hline AFG2 & $4(80)$ & $23.1-52.4$ & 35.5 & $3(100)$ & $13-36.8$ & 24.6 & nd & - & nd & $4(11)$ & $5.2-8.7$ & 6.6 & & 1 & \\
\hline HT-2 & $3(60)$ & $4.9-11$ & 7.6 & nd & - & nd & nd & - & nd & $4(11)$ & $5.3-7.1$ & 5.8 & & 5 & \\
\hline FB1 & $1(20)$ & up to 63.1 & na & $2(66.6)$ & $6.4-120$ & na & nd & - & nd & nd & - & nd & & 5 & \\
\hline FB2 & nd & - & nd & $1(33.3)$ & 61.5 & 61.5 & $1(7.6)$ & 6.4 & 6.4 & $1(3)$ & 8.7 & 8.7 & & 5 & \\
\hline \multirow[t]{3}{*}{ OTA } & nd & - & nd & nd & - & nd & $1(7.6)$ & 5 & 5 & nd & - & nd & & 5 & \\
\hline & \multicolumn{3}{|c|}{ Barley $(n=4)$} & \multicolumn{3}{|c|}{ Maize $(n=28)$} & \multicolumn{3}{|c|}{ Rice $(n=1)$} & \multicolumn{3}{|c|}{ Wheat $(n=21)$} & \multirow{2}{*}{ Analytical Method } & \multirow{2}{*}{$\underset{(\mu \mathrm{g} / \mathrm{kg})}{\mathrm{LOQ}}$} & \multirow[b]{2}{*}{ Ref. } \\
\hline & $I(\%)^{a}$ & $\begin{array}{l}\text { Range }{ }^{c} \\
(\mu \mathrm{g} / \mathrm{kg})\end{array}$ & $\begin{array}{l}\text { Mean b } \\
(\mu \mathrm{\mu g} / \mathrm{kg})\end{array}$ & I (\%) a & $\begin{array}{l}\text { Range c } \\
(\mu \mathrm{g} / \mathrm{kg})\end{array}$ & $\begin{array}{l}\text { Mean }{ }^{b} \\
(\mu g / k g)\end{array}$ & $I(\%)^{a}$ & $\begin{array}{l}\text { Range }{ }^{c} \\
(\mu \mathrm{g} / \mathrm{kg})\end{array}$ & $\begin{array}{c}\text { Mean } \\
(\mu \mathrm{g} / \mathrm{kg})\end{array}$ & $\mathrm{I}(\%)^{\mathrm{a}}$ & $\begin{array}{l}\text { Range } e^{c} \\
(\mu \mathrm{g} / \mathrm{kg})\end{array}$ & $\begin{array}{l}\text { Mean b } \\
(\mu \mathrm{\mu g} / \mathrm{kg})\end{array}$ & & & \\
\hline ENNA & nd & - & nd & nd & - & nd & $\mathrm{I}(\%)^{\mathrm{a}}$ & $\begin{array}{l}\text { Range } \\
(\mu \mathrm{g} / \mathrm{kg})\end{array}$ & $\begin{array}{c}\text { Meanc }^{c} \\
(\mu \mathrm{g} / \mathrm{kg})\end{array}$ & nd & - & nd & & 6 & \\
\hline ENNA1 & na & $\begin{array}{c}\text { up to } \\
361,570\end{array}$ & 148,160 & na & $\begin{array}{c}\text { up to } \\
813,010\end{array}$ & 167,700 & nd & - & nd & na & $\begin{array}{c}\text { up to } \\
634,850 \\
\end{array}$ & 225370 & & 4 & \\
\hline ENNB & $1(25)$ & $\begin{array}{l}\text { up to } \\
21,370\end{array}$ & 21370 & na & $\begin{array}{l}\text { up to } \\
6310\end{array}$ & 4470 & $1(100)$ & $\begin{array}{l}\text { up to } \\
814,410\end{array}$ & 814420 & nd & - & nd & LC-DAD & 4 & [51] \\
\hline ENNB1 & $1(25)$ & $\begin{array}{l}\text { up to } \\
4340\end{array}$ & 4340 & na & $\begin{array}{c}\text { up to } \\
21,370\end{array}$ & 21370 & $1(100)$ & $\begin{array}{l}\text { up to } \\
7950\end{array}$ & 7950 & nd & - & nd & & 5 & \\
\hline BEA & $2(50)$ & $\begin{array}{l}\text { up to } \\
6940 \\
\end{array}$ & 4870 & $6(21.4)$ & $\begin{array}{l}\text { up to } \\
9310\end{array}$ & 5720 & nd & - & nd & $9(42)$ & $\begin{array}{l}\text { up to } \\
3500\end{array}$ & 2300 & & 5 & \\
\hline \multirow[t]{3}{*}{ FUS } & nd & - & nd & na & $\begin{array}{l}\text { up to } \\
2470\end{array}$ & 2470 & $1(100)$ & $\begin{array}{l}\text { up to } \\
11780\end{array}$ & 11780 & na & $\begin{array}{l}\text { up to } \\
6630\end{array}$ & 3120 & & 6 & \\
\hline & \multicolumn{3}{|c|}{ Maize $(n=136)$} & & ghum $(n=$ & & & Gillet $(n=87$ & & & $\operatorname{gi~}(n=30$ & & Itic lothod & LOQ & 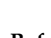 \\
\hline & $I(\%)^{a}$ & $\begin{array}{l}\text { Range c } \\
(\mu \mathrm{g} / \mathrm{kg})\end{array}$ & $\begin{array}{l}\text { Mean }{ }^{b} \\
(\mu g / k g)\end{array}$ & $I(\%)^{a}$ & $\begin{array}{l}\text { Range }^{c} \\
(\mu \mathrm{g} / \mathrm{kg})\end{array}$ & $\begin{array}{l}\text { Mean }{ }^{\mathrm{b}} \\
(\mu \mathrm{g} / \mathrm{kg})\end{array}$ & $I(\%)^{a}$ & $\begin{array}{l}\text { Range c } \\
(\mu \mathrm{g} / \mathrm{kg})\end{array}$ & $\begin{array}{c}\text { Mean } \\
(\mu \mathrm{\mu} / \mathrm{kg})\end{array}$ & $I(\%)^{a}$ & $\begin{array}{l}\text { Range c } \\
(\mu \mathrm{g} / \mathrm{kg})\end{array}$ & $\begin{array}{l}\text { Mean }{ }^{b} \\
(\mu g / k g)\end{array}$ & Analy tical Mietnod & $(\mu \mathrm{g} / \mathrm{kg})$ & Ret. \\
\hline FB1 & (65) & $\begin{array}{l}\text { up to } \\
8222\end{array}$ & 541 & (8) & up to 78 & 64 & (9) & $\begin{array}{c}\text { up to } \\
18.172 \\
\end{array}$ & 2333 & (93) & $\begin{array}{l}\text { up to } \\
1903\end{array}$ & 590 & & $16.4-20$ & \\
\hline $\mathrm{FB} 2$ & (54) & $\begin{array}{l}\text { up to } \\
2885\end{array}$ & 376 & (2) & up to 55 & 48 & (13) & $\begin{array}{l}\text { up to } \\
3892\end{array}$ & 609 & (87) & $\begin{array}{l}\text { up to } \\
1283\end{array}$ & 472 & & 22.6-24.2 & \\
\hline FB3 & (43) & up to 445 & 117 & (2) & up to 46 & 38 & nd & - & nd & (77) & up to 371 & 121 & LC-MS/MS & 28 & [43] \\
\hline DON & (16) & up to 225 & 99 & (3) & up to 119 & 100 & (13) & up to 543 & 151 & (13) & up to 74 & 61 & & $14-24$ & \\
\hline 15-AcDON & nd & - & nd & (2) & up to 44 & 39 & (1) & up to 11 & 11 & nd & - & nd & & $8.8-14$ & \\
\hline DON-3G & nd & - & nd & (23) & up to 63 & 24 & nd & - & nd & (17) & up to 44 & 30 & & $7.54-30.6$ & \\
\hline
\end{tabular}


Table 3. Cont.

\begin{tabular}{|c|c|c|c|c|c|c|c|c|c|c|c|c|c|c|c|}
\hline & \multicolumn{3}{|c|}{ Maize $(n=136)$} & \multicolumn{3}{|c|}{ Sorghum $(n=110)$} & \multicolumn{3}{|c|}{ Millet $(n=87)$} & \multicolumn{3}{|c|}{ Ogi $(n=30)$} & \multirow{2}{*}{ Analytical Method } & \multirow{2}{*}{$\underset{(\mu \mathrm{LO} / \mathrm{kg})}{\mathrm{LOQ}}$} & \multirow{2}{*}{ Ref. } \\
\hline & $\mathrm{I}(\%)^{\mathrm{a}}$ & $\begin{array}{l}\text { Range }^{\mathrm{c}} \\
(\mu \mathrm{g} / \mathrm{kg})\end{array}$ & $\begin{array}{l}\text { Mean } \\
(\mu \mathrm{g} / \mathrm{kg})\end{array}$ & $\mathrm{I}(\%)^{\mathrm{a}}$ & $\begin{array}{l}\text { Range }^{\mathrm{c}} \\
(\mu \mathrm{g} / \mathrm{kg})\end{array}$ & $\begin{array}{l}\text { Mean }{ }^{b} \\
(\mu \mathrm{g} / \mathrm{kg})\end{array}$ & $I(\%)^{a}$ & $\begin{array}{l}\text { Range }{ }^{c} \\
(\mu \mathrm{g} / \mathrm{kg})\end{array}$ & $\begin{array}{c}\text { Mean } \\
(\mu \mathrm{g} / \mathrm{kg})\end{array}$ & I $(\%)^{a}$ & $\begin{array}{l}\text { Range }^{\mathrm{c}} \\
(\mu \mathrm{g} / \mathrm{kg})\end{array}$ & $\begin{array}{l}\text { Mean }{ }^{b} \\
(\mu \mathrm{g} / \mathrm{kg})\end{array}$ & & & \\
\hline ZEN & (1) & up to 65 & 65 & (1) & up to 38 & 38 & (14) & $\begin{array}{l}\text { up to } \\
1399\end{array}$ & 419 & (3) & up to 39 & 39 & & $6.5-7.7$ & \\
\hline ZEN-14G & (9) & up to 24 & 21 & (3) & up to 22 & 19 & (6) & up to 34 & 23 & (3) & up to 31 & 31 & & $9.2-10.2$ & \\
\hline$\alpha-\mathrm{ZEN}$ & (1) & up to 20 & 20 & (3) & up to 33 & 33 & nd & - & nd & (7) & up to 22 & 20 & & $10-14$ & \\
\hline$\beta$-ZEN & (2) & up to 21 & 20 & (1) & up to 21 & 21 & (1) & up to 39 & 39 & (10) & up to 20 & 19 & & $14.4-16$ & \\
\hline HT-2 & (1) & up to 20 & 20 & (8) & up to 31 & 20 & (5) & up to 36 & 36 & (3) & up to 13 & 13 & & 13 & \\
\hline NIV & (2) & up to 271 & 206 & nd & - & nd & nd & - & nd & (7) & up to 160 & 148 & & $175-162.6$ & \\
\hline FUS- $\mathrm{X}$ & (1) & up to 154 & 154 & nd & - & nd & nd & - & nd & (7) & up to 133 & 137 & & $41.2-147.2$ & \\
\hline \multirow[t]{3}{*}{ DAS } & (13) & up to 8 & 3 & (18) & up to 16 & 5 & (29) & up to 25 & 5 & nd & - & nd & & $0.64-1$ & \\
\hline & \multicolumn{3}{|c|}{ Barley $(n=34)$} & \multicolumn{3}{|c|}{ Maize $(n=63)$} & \multicolumn{3}{|c|}{ Oats $(n=33)$} & \multicolumn{3}{|c|}{ Wheat $(n=51)$} & \multirow{2}{*}{ Analytical Method } & \multirow{2}{*}{$\underset{(\mu \mathrm{LO} / \mathrm{kg})}{\mathrm{LOQ}}$} & \multirow{2}{*}{ Ref. } \\
\hline & $I(\%)^{a}$ & $\begin{array}{l}\text { Range c } \\
(\mu g / k g)\end{array}$ & $\begin{array}{l}\text { Mean }{ }^{b} \\
(\mu g / k g)\end{array}$ & $I(\%)^{a}$ & $\begin{array}{l}\text { Range }^{c} \\
(\mu \mathrm{g} / \mathrm{kg})\end{array}$ & $\begin{array}{l}\text { Mean b } \\
(\mu \mathrm{g} / \mathrm{kg})\end{array}$ & $I(\%)^{a}$ & $\begin{array}{l}\text { Range }{ }^{\mathrm{c}} \\
(\mu \mathrm{g} / \mathrm{kg})\end{array}$ & $\begin{array}{c}\text { Mean } \\
(\mu \mathrm{\mu} / \mathrm{kg})\end{array}$ & $I(\%)^{a}$ & $\begin{array}{l}\text { Range }{ }^{c} \\
(\mu \mathrm{g} / \mathrm{kg})\end{array}$ & $\begin{array}{l}\text { Mean }{ }^{b} \\
(\mu g / k g)\end{array}$ & & & \\
\hline DON & (53) & $74-228$ & 342 & (71) & 215-2942 & 1565 & (21) & 34-201 & 145 & $(65)$ & $115-278$ & 223 & \multirow{4}{*}{ ELISA-UV } & 20.5 & \multirow{4}{*}{ [39] } \\
\hline ZEN & (9) & $5-68$ & 32 & (78) & $10-611$ & 187 & (6) & $4-43$ & 17 & (69) & $7-107$ & 56 & & 2.1 & \\
\hline FUS- $\mathrm{X}$ & (15) & $25-121$ & 44 & (90) & $37-4434$ & 1756 & (6) & $25-31$ & 28 & (39) & $28-203$ & 66 & & 24.5 & \\
\hline \multirow[t]{3}{*}{$\mathrm{T}-2$} & (32) & $5-26$ & 13 & (57) & $5-42$ & 24 & (18) & $5-10$ & 7 & (25) & $6-18$ & 9 & & 4.1 & \\
\hline & \multicolumn{3}{|c|}{ Barley $(n=20)$} & \multicolumn{3}{|c|}{ Maize $(n=20)$} & \multicolumn{3}{|c|}{ Wheat $(n=20)$} & & & & \multirow{2}{*}{ Analytical Method } & \multirow{2}{*}{$\underset{(\mu \mathrm{g} / \mathrm{kg})}{\mathrm{LOQ}}$} & \multirow{2}{*}{ Ref. } \\
\hline & I $(\%)^{a}$ & $\begin{array}{l}\text { Range }{ }^{c} \\
(\mu g / k g)\end{array}$ & $\begin{array}{l}\text { Mean b } \\
(\mu g / k g)\end{array}$ & $I(\%)^{a}$ & $\begin{array}{l}\text { Range }^{c} \\
(\mu g / \mathrm{kg})\end{array}$ & $\begin{array}{l}\text { Mean b } \\
(\mu \mathrm{g} / \mathrm{kg})\end{array}$ & $I(\%)^{a}$ & $\begin{array}{l}\text { Range c } \\
(\mu \mathrm{g} / \mathrm{kg})\end{array}$ & $\begin{array}{c}\text { Mean } \\
(\mu \mathrm{g} / \mathrm{kg})\end{array}$ & & & & & & \\
\hline OTA & $8(40)$ & up to 0.8 & 0.17 & $8(40)$ & up to 7.2 & 1.08 & $8(40)$ & up to 1.73 & 0.42 & & & & \multirow{3}{*}{ HPLC-FLD } & 0.02 & \multirow{3}{*}{ [45] } \\
\hline ZEN & na & - & na & $3(15)$ & up to 17 & 14 & na & - & na & & & & & 10 & \\
\hline \multirow[t]{3}{*}{ FB1 } & na & - & na & $10(50)$ & $\begin{array}{l}\text { up to } \\
5960\end{array}$ & 1930 & na & - & na & & & & & 60 & \\
\hline & Maize & sed produc & $(n=17)$ & Rice & ed produc & $n=9)$ & Whea & ased prodt & $(n=7)$ & & & & olutind & LOQ & \\
\hline & $\mathrm{I}(\%)^{\mathrm{a}}$ & $\begin{array}{l}\text { Range }^{\mathrm{c}} \\
(\mu \mathrm{g} / \mathrm{kg})\end{array}$ & $\begin{array}{l}\text { Mean }{ }^{\mathrm{b}} \\
(\mu \mathrm{g} / \mathrm{kg})\end{array}$ & $I(\%)^{a}$ & $\begin{array}{l}\text { Range }^{c} \\
(\mu \mathrm{g} / \mathrm{kg})\end{array}$ & $\begin{array}{l}\text { Mean }{ }^{\mathrm{b}} \\
(\mu \mathrm{g} / \mathrm{kg})\end{array}$ & $I(\%)^{a}$ & $\begin{array}{l}\text { Range }^{\mathrm{c}} \\
(\mu \mathrm{g} / \mathrm{kg})\end{array}$ & $\begin{array}{c}\text { Mean } \\
(\mu \mathrm{g} / \mathrm{kg})\end{array}$ & & & & Andatycan Mietioud & $(\mu \mathrm{g} / \mathrm{kg})$ & Ker. \\
\hline ENNA & nd & - & nd & nd & - & nd & nd & - & nd & & & & & 6 & \\
\hline ENNA1 & na & 423,600 & 113,000 & na & 61,400 & 55,100 & $1(14)$ & $\begin{array}{c}\text { up to } \\
46,900\end{array}$ & 46,900 & & & & & 4 & \\
\hline ENNB & nd & - & nd & $1(11)$ & 1050 & 1050 & nd & - & nd & & & & LC-DAD & 4 & {$[8]$} \\
\hline ENNB1 & $1(5.8)$ & 20,100 & 20100 & $1(11)$ & 600 & 600 & na & $\begin{array}{l}\text { up to } \\
79500\end{array}$ & 79500 & & & & Le & 5 & 101 \\
\hline BEA & nd & - & nd & nd & - & nd & nd & - & nd & & & & & 5 & \\
\hline FUS & nd & - & nd & $1(11)$ & 3900 & 3900 & nd & - & nd & & & & & 6 & \\
\hline
\end{tabular}

a Incidence of samples $\geq$ LOQ (\% of samples $\geq$ LOQ); ${ }^{\text {b }}$ minimum value - maximum; ${ }^{\mathrm{c}}$ Mean value for samples $\geq$ LOQ; $n$ : Number of samples; nd: Not detected; na: Not available; DAD: diode array detector; 3 -acetyl-deoxynivalenol (3-AcDON), 15-acetyl-deoxynivalenol (15-AcDON), neosolaniol (NEO), diacetoxyscirpenol (DAS), $\alpha$-zearalenol ( $\alpha$-ZEN), $\beta$-zearalanol ( $\beta$-ZEN), fusaproliferin (FUS), zearalenone-14-glucoside (ZEN-14G), fumonisin B3 (FB3), deoxynivalenol-3-glucoside (DON-3G), enniatin B4 (ENNB4), Nivalenol (NIV). 
These results demonstrated that it is not unusual to find cereals contaminated with several mycotoxins, and evidenced the human exposure to multiple mycotoxins [9,11-13]. Therefore, these findings point out the necessity of more toxicity studies that consider co-exposure to multiple mycotoxins, to detect possible synergism and additive effects and its consequent potential impact for public health.

\subsection{Exposure Estimates}

The dietary exposure to the studied mycotoxins was evaluated by calculating the probable daily intake (PDI), which combines mycotoxins analysis data obtained from the analysed samples with the food consumption of the adult population with a body weight of $60 \mathrm{~kg}$ [55].

The PDI ( $\mu \mathrm{g} / \mathrm{kg}$ per body weight (bw)/day) of each mycotoxin was calculated using the following equation [55]:

$$
\mathrm{PDI}=(\mathrm{Cm} \times \mathrm{K}) / \mathrm{bw}
$$

where $\mathrm{C}_{\mathrm{m}}$ is the mean content of a mycotoxin in the cereal $(\mu \mathrm{g} / \mathrm{kg}) ; \mathrm{K}$ is the average consumption of the commodity (g/day) and bw is the body weight used for adult population.

Once the PDI had been calculated, the health risk characterization of each mycotoxin ( $\%$ of relevant TDI) was estimated as the ratio of PDI to TDI $(\mu \mathrm{g} / \mathrm{kg}$ bw/day) for each mycotoxin as follows:

$$
\% \mathrm{TDI}=(\mathrm{PDI} / \mathrm{TDI}) \times 100
$$

The PMTDI or TDI and the provisional tolerable weekly intake (PTWI) set by both the FAO/WHO JECFA and the Scientific Committee on Food (SCF), were used as reference doses $[19,20]$. Data on consumption of barley ( $36 \mathrm{~g} /$ day), maize ( $44 \mathrm{~g} /$ day), rice $(8 \mathrm{~g} /$ day) and wheat (502 g/day) by Algerian population were mainly obtained from FAO statistical study [56]. The results obtained are summarised in Table 4.

Table 4. Results of the probable daily intake (PDI) assessment of the studied mycotoxins.

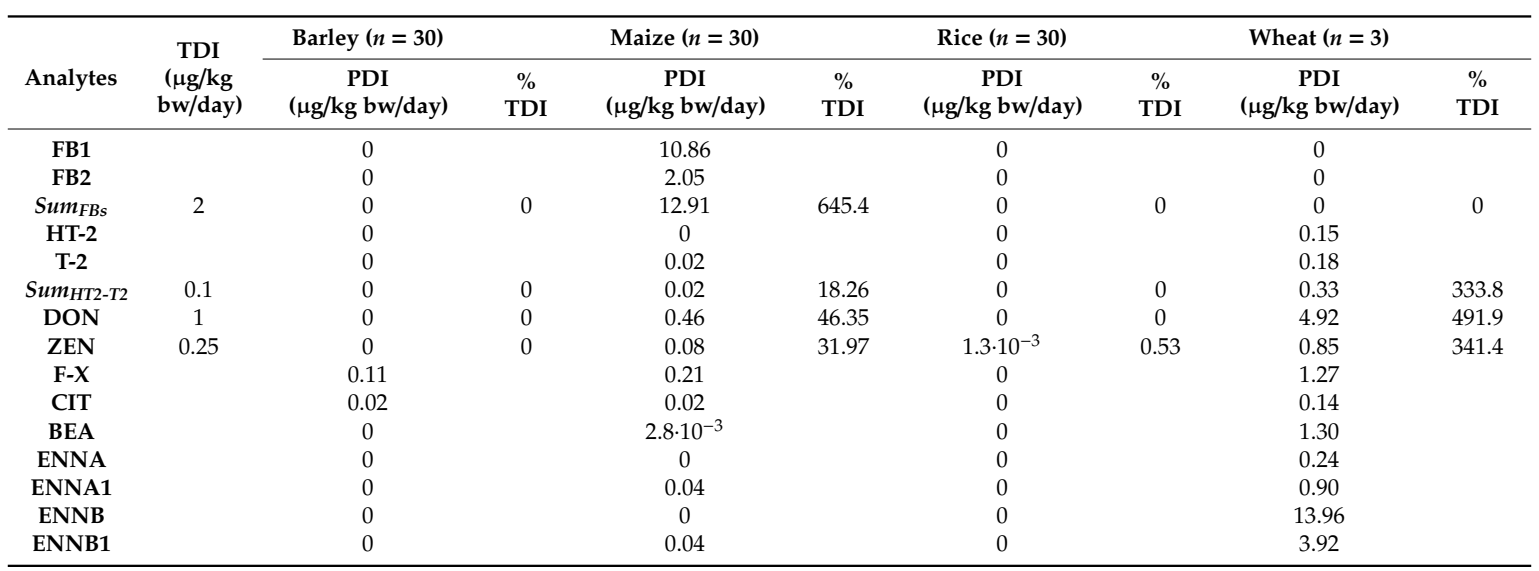

From the PDI values, it can be concluded that maize and wheat samples represent an important dietary exposure of mycotoxins for the Algerian population, with a dietary exposure range of $2.8 \times$ $10^{-3}-12.91$ ( $\mu \mathrm{g} / \mathrm{kg}$ bw/day) and 0.14-13.96 ( $\mu \mathrm{g} / \mathrm{kg}$ bw/day) in maize and wheat, respectively. In these samples, the obtained values for FB1 $(10.86 \mu \mathrm{g} / \mathrm{kg}$ bw/day) in maize and ENNB $(13.96 \mu \mathrm{g} / \mathrm{kg}$ bw/day) in wheat were the highest contribution for the PDI of mycotoxins for the Algerian population.

The exposure assessment was evaluated for all the mycotoxins with TDI available, namely DON, FB1+ FB2, ZEN, T-2 + HT-2 (see Table 4). The results showed that Algerian consumers present at a high risk of exposure to the sum of fumonisins (FB1 + FB2) through maize consumption (\%TDI of 645.4), and to DON, ZEN and the sum of (HT-2 + T-2) through wheat consumption with \%TDI of 491.9, 341.4 and 333.8, respectively. These values are several-hundred fold higher than the values established 
by JECFA for FB1 + FB2 (PMTDI of $2 \mu \mathrm{g} / \mathrm{kg}$ bw/day), DON (PMTDI of $1 \mu \mathrm{g} / \mathrm{kg}$ bw/day), ZEN (TDI of $0.25 \mu \mathrm{g} / \mathrm{kg}$ bw/day) and for the sum of HT-2 and T-2 toxins (TDI of $0.1 \mu \mathrm{g} / \mathrm{kg}$ bw/day).

These findings suggest that the intake of mycotoxins from analysed maize and wheat samples represent a high health risk for the average adult consumers in Algeria and pointed towards the necessity for a consistent control over these contaminants.

These results are globally in line with other studies from African countries; for instance, a study performed in Tanzania reported that fumonisin exposures to adult individuals in $38 \%$ of the households exceeded the provisional maximum tolerable daily intake (PMTDI) of $2 \mu \mathrm{g} / \mathrm{kg}$ bw based on the fumonisins (FB1 + FB2) concentration of up to $11 \mathrm{mg} / \mathrm{kg}$ in the maize grains [57]. Similar results were found for fumonisins (FB1 + FB2 + FB3) dietary exposure of $12.4 \mu \mathrm{g} / \mathrm{kg}$ bw/day in Nigerian infants and $8.2 \mu \mathrm{g} / \mathrm{kg}$ bw/day in children by maize intake with \%TDI of 622.2 and 414.8, which were 311 and 207 times higher than the tolerable daily intake of $2 \mu \mathrm{g} / \mathrm{kg} \mathrm{bw} /$ day [58].

Moreover, high attention should be devoted to the health risk scenarios for consumers in the case of co-exposures to multiple mycotoxins. However, the effect of co-occurrence of mycotoxins have not been well understood yet. These effects could be additive, synergistic and can vary with dose, exposure time, and toxicological end point [9].

\section{Conclusions}

In this study, a LC-MS/MS analytical method for determination of 15 mycotoxins in cereals has been applied to provide data on the occurrence of these hazards in barley, maize, rice and wheat from Algeria. Moreover, the risk associated with the exposure to mycotoxins through intake of cereal products has been estimated.

Results on mycotoxins occurrence showed that $65 \%$ of the samples were contaminated with at least one mycotoxin. The maximum acceptable levels established in EU where exceeded in 21 samples (70\%) for fumonisins (4000 $\mu \mathrm{g} / \mathrm{kg}$ of FB1 + FB2 in maize), 8 samples for ZEN (100 $\mu \mathrm{g} / \mathrm{kg}$ for maize and 350 for other unprocessed cereals) and 1 sample for DON (1750 $\mu \mathrm{g} / \mathrm{kg}$ for wheat and maize) [18]. Co-contamination was observed in 50\% of the analysed samples (all maize and wheat samples). Among them, some samples were contaminated with up to 9 mycotoxins. Due to these high levels of contamination, this study concluded that the Algerians are at high risk of exposure to the sum of fumonisins (FB1 + FB2) through the consumption of maize, and to DON, ZEN and the sum of (HT-2 + T-2) through the consumption of wheat. Therefore, preventive approaches to curtail health risks associated with mycotoxins exposures are needed, which requires, at first instance, government intervention. The analytical results of this survey should encourage Algerian authorities to introduce allowed maximum limits of mycotoxins in cereals. In our opinion, continuous monitoring of these mycotoxins with a higher number of samples and other susceptible foodstuffs (such as cereal-based products, nuts or dried fruits) are recommended to assess the situation, at least for such a time until proper regulatory limits are set. On the other hand, the focus should also be directed towards reduction and control of mycotoxins producing fungi in the food chain.

\section{Materials and Methods}

\subsection{Reagents and Materials}

Methanol $(\mathrm{MeOH})$ and acetonitrile $(\mathrm{MeCN})$ of LC-MS grade, and ammonium formate were supplied by VWR International Eurolab S.L. (Barcelona, Spain). Formic acid eluent additive for LC-MS was obtained from Sigma Aldrich (St. Louis, MO, USA). Magnesium sulphate $\left(\mathrm{MgSO}_{4}\right)$, sodium chloride $(\mathrm{NaCl})$ and sodium citrate were purchased from Panreac Química (Barcelona, Spain), while disodium hydrogen citrate sesquihydrate was supplied by Merck (Darmstadt, Germany). Ultrapure water was obtained from a Milli-Q Plus system (Millipore Bedford, MA, USA).

Mycotoxin standard solutions (10 mg/L in MeCN) of OTA, STE, F-X, DON, CIT, ZEN, FB1, FB2, T-2 and HT-2 were purchased from Techno Spec (Barcelona, Spain). Individual standards (powder) 
of ENNA, ENNA1, ENNB, ENNB1 and BEA were obtained from Sigma Aldrich and stock solutions were prepared at $1000 \mathrm{mg} / \mathrm{L}$ in MeCN. Multi-mycotoxins intermediate working solutions in MeCN $(1 \mathrm{mg} / \mathrm{L}$ of OTA and STE; $2 \mathrm{mg} / \mathrm{L}$ of CIT; $10 \mathrm{mg} / \mathrm{L}$ of FB1, FB2, T-2, HT-2 and ZEN; $100 \mathrm{mg} / \mathrm{L}$ of DON, ENNA, ENNA1, ENNB, ENNB1 and BEA and $1000 \mathrm{mg} / \mathrm{L}$ of F-X) were prepared by combining suitable aliquots of each individual standard stock solution. These solutions were stored at $-20{ }^{\circ} \mathrm{C}$.

Nylon syringe filters ( $13 \mathrm{~mm}, 0.22 \mu \mathrm{m}$, from VWR) were used for filtration of extracts prior to the injection into the chromatographic system.

\subsection{Instruments and Equipment}

UHPLC-MS/MS analyses were performed in an Agilent 1290 Infinity LC (Agilent Technologies, Waldbronn, Germany) coupled to an API 3200 triple quadrupole mass spectrometer (AB Sciex, Darmstadt, Germany) with electrospray ionization (ESI). The chromatographic separation was performed using an Agilent Zorbax Eclipse Plus RRHD C18 column $(50 \times 2.1 \mathrm{~mm}, 1.8 \mu \mathrm{m})$. Analyst software (Version 1.6.3, AB Sciex, Darmstadt, Germany) was used for acquisition and data analysis.

During the sample treatment, an evaporator System (System EVA-EC, from VLM GmbH, Bielefeld, Germany), a vortex-2 Genie (Scientific Industries, Bohemia, NY, USA), a universal 320R centrifuge (Hettich ZENtrifugen, Tuttlingen, Germany), and a kitchen blender were used.

\subsection{Samples}

A total of 120 cereal samples (barley, maize, rice and wheat) destined for human consumption were randomly purchased from different local markets in three areas of the western region of Algeria-Aint Temouchent, Oran and Tiaret—during the year 2018 (see Table 5). In order to obtain representative samples, several sub-samples were taken from each batch, being thoroughly mixed to achieve a final 1-kg sample. Finally, the samples were grinded, homogenized and stored in a dark and dry place until analysis.

Table 5. Sampling information.

\begin{tabular}{ccccc}
\hline Sample Type & Selected Areas & No. of Markets & No. of Samples & Origin \\
\hline \multirow{3}{*}{ Barley } & Aint Temouchent & 5 & 10 & OAIC \\
& Oran & 7 & 10 & 10 \\
Tiaret & 8 & Total $=30$ & \\
& & & 10 & Imported \\
Maize & Aint Temouchent & 7 & 10 & \\
& Oran & 6 & 10 & \\
& Tiaret & 8 & Total $=30$ & Imported \\
Rice & Aint Temouchent & 10 & 10 & \\
& Oran & 7 & 10 & Notal $=30$ \\
Tiaret & 10 & 10 & 10 \\
Wheat & Aint Temouchent & 6 & 10 & \\
& Oran & 9 & Total $=30$ & \\
\hline
\end{tabular}

OAIC: Office Algérien interprofessionnel des céréales, NG: not given.

\subsection{Mycotoxins Extraction Procedure}

A previous method was used for the extraction of mycotoxins in the different samples [59]. Briefly, $2 \mathrm{~g}$ of grounded sample were weighed in a polypropylene centrifuge tube $(50 \mathrm{~mL}), 8 \mathrm{~mL}$ of water was added, and the mixture was vortexed for $10 \mathrm{~s}$. Subsequently, $10 \mathrm{~mL}$ of $5 \%$ formic acid in $\mathrm{MeCN}$ was 
added to the tube, shaking by vortex for $2 \mathrm{~min}$. Then, $4 \mathrm{~g}$ of $\mathrm{MgSO}_{4}, 1 \mathrm{~g}$ of $\mathrm{NaCl}, 1 \mathrm{~g}$ of sodium citrate and $0.5 \mathrm{~g}$ of disodium hydrogen citrate sesquihydrate were added and the tube was shaken vigorously for $1 \mathrm{~min}$. After centrifugation at $4500 \mathrm{rpm}(3722 \times \mathrm{g})$ for $5 \mathrm{~min}, 2 \mathrm{~mL}$ of the upper supernatant layer was transferred to a 4-mL vial, evaporated to dryness under a gentle stream of nitrogen, and reconstituted to a final volume of $1 \mathrm{~mL}$ with a mixture of MeOH:water (50:50, v/v). The samples were filtered before injection and the 15 mycotoxins were determined by UHPLC-MS/MS. A graphical scheme of the procedure is shown in Figure 1.

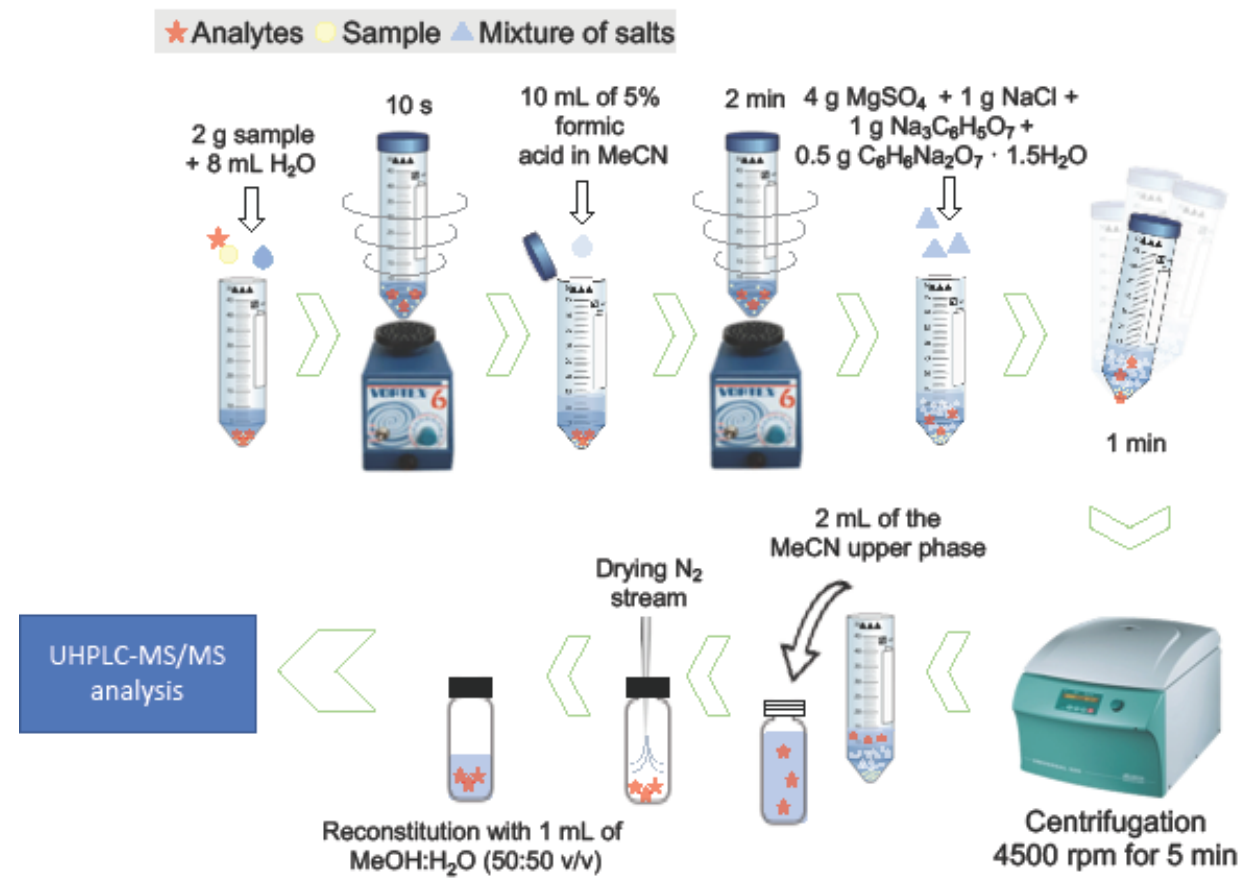

Figure 1. Graphical scheme of the extraction procedure.

\subsection{Ultra-High Performance Liquid Chromatography Coupled to Tandem Mass Spectrometry (UHPLC-MS/MS) Analysis}

Chromatographic analyses were performed using a gradient elution with water (phase A), and $\mathrm{MeOH}$ (phase $\mathrm{B}$ ), both containing $0.3 \%$ formic acid and $5 \mathrm{mM}$ ammonium formate, at a flow rate of $0.4 \mathrm{~mL} / \mathrm{min}$. The gradient elution program was as follows: $0-1 \mathrm{~min}, 5 \% \mathrm{~B} ; 4 \mathrm{~min}, 50 \% \mathrm{~B} ; 5 \mathrm{~min}, 80 \% \mathrm{~B}$; $5.5 \mathrm{~min}, 90 \% \mathrm{~B} ; 5.7 \mathrm{~min}, 5 \% \mathrm{~B} ; 5.7-8 \mathrm{~min}, 5 \% \mathrm{~B}$. The temperature of the column was kept at $35^{\circ} \mathrm{C}$ and the injection volume was $5 \mu \mathrm{L}$.

The electrospray ionization was carried out in in the positive mode and the acquisition was performed under multiple reaction monitoring (MRM) conditions. The ionization source parameters were set as follows: source temperature: $500^{\circ} \mathrm{C}$; curtain gas (nitrogen): $30 \mathrm{psi}$; ion spray voltage: $5000 \mathrm{~V}$; and GAS 1 and GAS 2 (both of them nitrogen): 50 psi. The applied cone voltages and collision energies for each mycotoxin are summarized in the supplementary material (Table S4). In all cases, the most abundant product ion was used for quantification, while the second one was used for confirmation.

Supplementary Materials: The following are available online at http://www.mdpi.com/2072-6651/12/3/194/s1, Figure S1: Matrix effect (\%) for each studied mycotoxin extracted from barley, maize, rice and wheat samples (concentration levels: OTA and STE: $25 \mu \mathrm{g} / \mathrm{kg}$; CIT: $100 \mu \mathrm{g} / \mathrm{kg}$; FB1, FB2, T-2, HT-2 and ZEN: $250 \mu \mathrm{g} / \mathrm{kg}$; ENNB, ENNB1, ENA, ENA1 and BEA: $400 \mu \mathrm{g} / \mathrm{kg}$, DON: $1000 \mu \mathrm{g} / \mathrm{kg}$ and FUS-X: $2500 \mu \mathrm{g} / \mathrm{kg}$ ); Figure S2: UHPLC-MS/MS MRM chromatogram of two samples of positive wheat contaminated with (A) DON (1362 $\mu \mathrm{g} / \mathrm{kg}$ ) and (B) ENNB1 $(419 \mu \mathrm{g} / \mathrm{kg})$; Table S1: Performance characteristics of the UHPLC-MS/MS method for each mycotoxin in barley, maize, rice and wheat samples; Table S2: Recovery (\%R), intra-day precision $\left(\% \mathrm{RSD}_{\mathrm{r}}\right)$ and inter-day precision $\left(\% \mathrm{RSD}_{\mathrm{R}}\right)$ for barley, maize, rice and wheat samples $(n=9)$; Table S3: Co-occurrence of analysed mycotoxins in wheat and maize samples; Table S4: Monitored ions of the target analytes and MS/MS parameters. 
Author Contributions: Conceptualization, L.G.-G., A.M.G.-C., C.K.M., N.H.-K. and K.M.; methodology, L.G.-G. and N.A.-M.; validation, C.K.M. and N.A.-M.; formal analysis, C.K.M. and N.A.-M.; investigation, C.K.M., N.A.-M. and L.G.-G.; resources, A.M.G.-C.; writing-original draft preparation, C.K.M. and N.A.-M.; writing-review and editing, L.G.-G. and A.M.G.-C.; visualization, C.K.M. and L.G.-G.; supervision, A.M.G.-C. and L.G.-G.; project administration, A.M.G.-C.; funding acquisition, A.M.G.-C. All authors have read and agreed to the published version of the manuscript.

Funding: This research was funded by SPANISH MINISTRY OF ECONOMY AND COMPETITIVENESS and EUROPEAN REGIONAL DEVELOPMENT FUND (MINECO/FEDER, UE) (Project ref: AGL2015-70708-R, MINECO/FEDER, UE). Choukri Khelifa Mahdjoubi would like to thanks the University of Granada for ERASMUS Mundus Doctoral Fellowship.

Conflicts of Interest: The authors declare no conflict of interest.

\section{References}

1. Ostry, V.; Malir, F.; Toman, J.; Grosse, Y. Mycotoxins as human carcinogens-The IARC Monographs classification. Mycotoxin Res. 2017, 33, 65-73. [CrossRef] [PubMed]

2. Zain, M.E. Impact of mycotoxins on humans and animals. J. Saudi Chem. Soc. 2011, 15, 129-144. [CrossRef]

3. De Boevre, M.; Diana Di Mavungu, J.; Landschoot, S.; Audenaert, K.; Eeckhoutn, M.; Maene, P.; Haesaert, G.; De Saeger, S. Natural occurrence of mycotoxins and their masked forms in food and feed products. World Mycotoxin J. 2012, 5, 207-219. [CrossRef]

4. Otto, K.; Santini, A.; Oancea, S. Recent aflatoxin survey data in milk and milk products: A review. Int. J. Dairy Technol. 2017, 70, 1-12. [CrossRef]

5. Mikušová, P.; Šrobárová, A.; Sulyok, M.; Santini, A. Fusarium fungi and associated metabolites presence on grapes from Slovakia. Mycotoxin Res. 2013, 29, 97-102. [CrossRef]

6. Gruber-Dorninger, C.; Novak, B.; Nagl, V.; Berthiller, F. Emerging mycotoxins: Beyond traditionally determined food contaminants. J. Agric. Food Chem. 2017, 65, 7052-7070. [CrossRef]

7. Jajić, I.; Dudaš, T.; Krstovic, S.; Krska, R.; Sulyok, M.; Bagi, F.; Savić, Z. Emerging Fusarium mycotoxins fusaproliferin, beauvericin, enniatins, and moniliformin in Serbian maize. Toxins 2019, 11, 357. [CrossRef]

8. Mahnine, N.; Meca, G.; Elabidi, A.; Fekhaoui, M.; Saoiabi, A.; Font, G.; Mañes, J.; Zinedine, A. Further data on the levels of emerging Fusarium mycotoxins enniatins (A, A1, B, B1), beauvericin and fusaproliferin in breakfast and infant cereals from Morocco. Food Chem. 2011, 124, 481-485. [CrossRef]

9. Grenier, B.; Oswald, I.P. Mycotoxin co-contamination of food and feed: Meta-analysis of publications describing toxicological interactions. World Mycotoxin J. 2011, 4, 285-313. [CrossRef]

10. Lee, H.J.; Ryu, D. Worldwide occurrence of mycotoxins in cereals and cereal-derived food products: Public health perspectives of their co-occurrence. J. Agric. Food Chem. 2017, 65, 7034-7051. [CrossRef]

11. Assunção, R.; Silva, M.J.; Alvito, P. Challenges in risk assessment of multiple mycotoxins in food. World Mycotoxin J. 2016, 9, 791-811. [CrossRef]

12. Alassane-Kpembi, I.; Schatzmayr, G.; Taranu, I.; Marin, D.; Puel, O.; Oswald, I.P. Mycotoxins co-contamination: Methodological aspects and biological relevance of combined toxicity studies. Crit. Rev. Food Sci. Nutr. 2017, 57, 3489-3507. [CrossRef] [PubMed]

13. De Ruyck, K.; De Boevre, M.; Huybrechts, I.; De Saeger, S. Dietary mycotoxins, co-exposure, and carcinogenesis in humans: Short review. Mutat. Res. Rev. Mutat. Res. 2015, 766, 32-41. [CrossRef] [PubMed]

14. Smith, M.C.; Madec, S.; Coton, E.; Hymery, N. Natural co-occurrence of mycotoxins in foods and feeds and their in vitro combined toxicological effects. Toxins 2016, 8, 94. [CrossRef] [PubMed]

15. Tavares, A.M.; Alvito, P.; Loureiro, S.; Louro, H.; Silva, M.J. Multi-mycotoxin determination in baby foods and in vitro combined cytotoxic effects of aflatoxin M1 and ochratoxin A. World Mycotoxin J. 2013, 6, 375-388. [CrossRef]

16. Wan, L.Y.; Turner, P.C.; El-Nezami, H. Individual and combined cytotoxic effects of Fusarium toxins (deoxynivalenol, nivalenol, zearalenone and fumonisins B1) on swine jejunal epithelial cells. Food Chem. Toxicol. 2013, 57, 276-283. [CrossRef]

17. European Commission (EC). Commission recomendations of 27 March 2013 on the presence of T-2 and HT-2 toxin in cereals and cereal products. Off. J. Eur. Union. L 2013, 91, 12-15.

18. European Commission (EC). Commission regulation (EC) No 1881/2006 of 19 December 2006 setting maximum levels for certain contaminants in foodstuffs. Off. J. Eur. Union. 2006, 364, 5-24. 
19. JEFCA. Joint FAO/WHO Standards Programme Codex Committee on Contaminants in Food. Working Document for Information and Use in Discussions Related to Contaminants and Toxins in the GSCTFF. 2018. Available online: http//www.fao.org/fao-who-codexalimentarius/sh-proxy/en/?lnk=1\&url=https\% 253A\%252F\%252Fworkspace.fao.org\%252Fsites\%252Fcodex\%252FMeetings\%252FCX-735-12\%252FWD\% 252Fcf12_INF01x.pdf (accessed on 6 December 2019).

20. JEFCA. Joint FAO/WHO Expert Committee on Food Additives. Summary and Conclusion of Eighty-Third Meeting of the JEFCA. 2016. Available online: http://www.fao.org/3/BQ821E/bq821e.pdf (accessed on 6 December 2019).

21. U.S. Food and Drug Administration. Compliance Policy Guide Sec. 555.400 Foods-Adulteration with Aflatoxin. Available online: https:/www.fda.gov/Food/GuidanceRegulation/GuidanceDocumentsRegulatoryInformation/ ChemicalContaminantsMetalsNaturalToxinsPesticides/default.htm (accessed on 20 February 2020).

22. U.S. Food and Drug Administration. Guidance for Industry. Fumonisin Levels in Human Foods and Animal Feeds. Available online: https://www.fda.gov/Food/GuidanceRegulation/ GuidanceDocumentsRegulatoryInformation/ChemicalContaminantsMetalsNaturalToxinsPesticides/default. htm (accessed on 20 February 2020).

23. Canadian Food Inspection Agency. RG-8 Regulatory Guidance. Contaminants in Feed (Formerly RG-1, Chapter 7), Section 1: Mycotoxins in Livestock Feed. Available online: http:/www.inspection.gc.ca/animals/ feeds/regulatory-guidance/rg8/eng/1347383943203/1347384015909 (accessed on 20 February 2020).

24. Food and Agricultural Materials Inspection Centre (FAMIC). Aflatoxin. Available online: http://www.famic. go.jp/ffis/oie/obj/hc_aflatoxin.pdf (accessed on 20 February 2020).

25. Food and Agricultural Materials Inspection Centre (FAMIC). Regulation Value of Pesticides, Heavy Metals and Mycotoxins (Administrative Guideline). Available online: http://www.famic.go.jp/ffis/feed/r_safety/r_ feeds_safety22.html (accessed on 20 February 2020).

26. China Food Safety National Standard. Maximum Levels of Mycotoxins in Food, Released 17 March 2017, Implemented 17 September 2017. Available online: https://www.fas.usda.gov/data/china-china-releasesstandard-maximum-levels-mycotoxins-foods (accessed on 20 February 2020).

27. Bulletin Officiel. Arrêté Conjoint du Ministre de L'agriculture et de la Pêche Maritime et du Ministre de la Santé n 1643-16 du 23 Chaabane 1437 (30 Mai 2016) Fixant les Limites Maximales Autorisées des Contaminants dans les Produits Primaires et les Produits Alimentaires. Available online: http://www.onssa. gov.ma/fr/images/reglementation/transversale/ARR.1643-16.FR.pdf (accessed on 20 February 2020).

28. Santini, A.; Meca, G.; Ritieni, A. Fusaproliferin, beauvericin, and enniatins: Occurrence in food-A review. World Mycotoxin J. 2012, 5, 71-81. [CrossRef]

29. Santini, A.; Raiola, A.; Meca, G.; Ritieni, A. Aflatoxins, ochratoxins, trichothecenes, patulin, fumonisins and beauvericin in finished products for human consumption. J. Clin. Toxicol. 2015, 5, 265. [CrossRef]

30. Eskola, M.; Kos, G.; Elliott, C.T.; Hajšlová, J.; Mayar, S.; Krska, R. Worldwide contamination of food-crops with mycotoxins: Validity of the widely cited 'FAO estimate' of 25\%. Crit. Rev. Food Sci. Nutr. 2019, 3, 1-17. [CrossRef] [PubMed]

31. Tantaoui-Elaraki, A.; Riba, A.; Oueslati, S.; Zinedine, A. Toxigenic fungi and mycotoxin occurrence and prevention in food and feed in northern Africa-A review. World Mycotoxin J. 2018, 11, 385-400. [CrossRef]

32. Van Egmond, H.P.; Schothorst, R.C.; Jonker, M.A. Regulations relating to mycotoxins in food. Anal. Bioanal. Chem. 2007, 389, 147-157. [CrossRef] [PubMed]

33. Berthiller, F.; Cramer, B.; Iha, M.H.; Krska, R.; Lattanzio, V.M.T.; MacDonald, S.; Malone, R.J.; Maragos, C.; Solfrizzo, M.; Stranska-Zachariasova, M.; et al. Developments in mycotoxin analysis: An update for 2016-2017. World Mycotoxin J. 2018, 11, 5-31. [CrossRef]

34. Santini, A.; Ferracane, R.; Meca, G.; Ritieni, A. Overview of analytical methods for beauvericin and fusaproliferin in food matrices. Anal. Bioanal. Chem. 2009, 395, 1253-1260. [CrossRef]

35. Santini, A.; Ferracane, R.; Somma, M.C.; Somma, A.; Aragon, A.; Ritieni, A. Multitoxin extraction and detection of thricotecenes in cereals: An improved LC-MS/MS approach. J. Sci. Food Agric. 2009, 89, 1145-1153. [CrossRef]

36. Arroyo-Manzanares, N.; Huertas-Pérez, J.F.; García-Campaña, A.M.; Gámiz-Gracia, L. Review of sample treatments and the state-of-the-art of analytical techniques for mycotoxins in food. In Analysis of Food Toxins and Toxicants; Wong, Y.-C., Lewis, R.J., Eds.; John Wiley \& Sons Ltd.: New York, NY, USA, 2017; pp. 51-102. [CrossRef] 
37. European Commission (EC). Commission regulation (EC) No 401/2006 of 23 February 2006 laying down the methods of sampling and analysis for the official control of the levels of mycotoxins in foodstuffs. Off. J. Eur. Union. 2006, L70, 12-34.

38. Bouafifssa, Y.; Manyes, L.; Rahouti, M.; Mañes, J.; Berrada, H.; Zinedine, A.; Fernández-Franzón, M. Multi-occurrence of twenty mycotoxins in pasta and a risk assessment in the Moroccan population. Toxins 2018, 10, 432. [CrossRef]

39. Pleadin, J.; Vahčić, N.; Perši, N.; Ševelj, D.; Markov, K.; Frece, J. Fusarium mycotoxins' occurrence in cereals harvested from Croatian fields. Food Control 2013, 32, 49-54. [CrossRef]

40. Juan, C.; Ritieni, A.; Mañes, J. Occurrence of Fusarium mycotoxins in Italian cereal and cereal products from organic farming. Food Chem. 2013, 141, 1747-1755. [CrossRef]

41. Zaied, C.; Zouaoui, N.; Bacha, H.; Abid, S. Natural occurrence of zearalenone in Tunisian wheat grains. Food Control 2012, 25, 773-777. [CrossRef]

42. Savi, G.D.; Piacentini, K.C.; Rocha, L.O.; Carnielli-Queiroz, L.; Furtado, B.G.; Scussel, R.; Zanoni, E.T.; Machado de Ávila, R.A.; Corrêa, B.; Angioletto, E. Incidence of toxigenic fungi and zearalenone in rice grains from Brazil. Int. J. Food Microbiol. 2018, 270, 5-13. [CrossRef] [PubMed]

43. Chilaka, C.A.; De Boevre, M.; Atanda, O.O.; De Saeger, S. Occurrence of Fusarium mycotoxins in cereal crops and processed products (Ogi) from Nigeria. Toxins 2016, 8, 342. [CrossRef] [PubMed]

44. De Boevre, M.; Landschoot, S.; Audenaert, K.; Maene, P.; Diana Di Mavungu, J.; Eeckhout, M.; Haesaert, G.; De Saeger, S. Occurrence and within field variability of Fusarium mycotoxins and their masked forms in maize crops in Belgium. World Mycotoxin J. 2014, 7, 91-102. [CrossRef]

45. Zinedine, A.; Brera, C.; Elakhdari, S.; Catano, C.; Debegnach, F.; Angelini, S.; De Santis, B.; Faid, M.; Benlemlih, M.; Minardi, V.; et al. Natural occurrence of mycotoxins in cereals and spices commercialized in Morocco. Food Control 2006, 17, 868-874. [CrossRef]

46. Ghali, R.; Ghorbel, H.; Hedilli, A. Fumonisin determination in Tunisian foods and feeds. ELISA and HPLC methods comparison. J. Agric. Food Chem. 2009, 57, 3955-3960. [CrossRef]

47. Bryła, M.; Waśkiewicz, A.; Podolska, G.; Szymczyk, K.; Jędrzejczak, R.; Damaziak, K.; Sułek, A. Occurrence of 26 mycotoxins in the grain of cereals cultivated in Poland. Toxins 2016, 8, 160. [CrossRef]

48. Phoku, J.Z.; Dutton, M.F.; Njobeh, P.B.; Mwanza, M.; Egbuta, M.A.; Chilaka, C.A. Fusarium infection of maize and maize-based products and exposure of a rural population to fumonisin B1 in Limpopo Province, South Africa. Food Addit. Contam. Part A 2012, 29, 1743-1751. [CrossRef]

49. Tsehaye, H.; Brurberg, M.B.; Sundheim, L.; Assefa, D.; Tronsmo, A.; Tronsmo, A.M. Natural occurrence of Fusarium species and fumonisin on maize grains in Ethiopia. Eur. J. Plant Pathol. 2017, 147, 141-155. [CrossRef]

50. Houbraken, J.; De Vries, R.P.; Samson, R.A. Modern taxonomy of biotechnologically important Aspergillus and Penicillium species. Adv. Appl. Microbiol. 2014, 86, 199-249. [CrossRef]

51. Meca, G.; Zinedine, A.; Blesa, J.; Font, G.; Mañes, J. Further data on the presence of Fusarium emerging mycotoxins enniatins, fusaproliferin and beauvericin in cereals available on the Spanish markets. Food Chem. Toxicol. 2010, 48, 1412-1416. [CrossRef] [PubMed]

52. Oueslati, S.; Romero-González, R.; Lasram, S.; Garrido-Frenich, A.; Martínez-Vidal, J.L. Multi-mycotoxin determination in cereals and derived products marketed in Tunisia using ultra-high performance liquid chromatography coupled to triple quadrupole mass spectrometry. Food Chem. Toxicol. 2012, 50, 2376-2381. [CrossRef] [PubMed]

53. Blesa, J.; Moltó, J.C.; El Akhdari, S.; Mañes, J.; Zinedine, A. Simultaneous determination of Fusarium mycotoxins in wheat grain from Morocco by liquid chromatography coupled to triple quadrupole mass spectrometry. Food Control 2014, 46, 1-5. [CrossRef]

54. Rodríguez-Carrasco, Y.; Ruiz, M.J.; Font, G.; Berrada, H. Exposure estimates to Fusarium mycotoxins through cereals intake. Chemosphere 2013, 93, 2297-2303. [CrossRef] [PubMed]

55. International Programme on Chemical Safety (IPCS). Principles and Methods for the Risk Assessment of Chemicals in Food. In Environmental Health Criteria 240; WHO: Stuttgart, Germany, 2009; Available online: https://www.who.int/foodsafety/publications/chemical-food/en/ (accessed on 6 December 2019).

56. FAO Statistics Division (FAOSTAT). Food and Agricultural Commodities Production. Available online: http://faostat.fao.org/site/339/default.aspx (accessed on 10 January 2019). 
57. Kimanya, M.; De Meulenaer, B.; Tiisekwa, B.; Ndomondo-Sigonda, M.; Kolsteren, P. Human exposure to fumonisins from home grown maize in Tanzania. World Mycotoxin J. 2008, 1, 307-313. [CrossRef]

58. Adetunji, M.C.; Atanda, O.O.; Ezekiel, C.N. Risk assessment of mycotoxins in stored maize grains consumed by infants and young children in Nigeria. Children 2017, 4, 58. [CrossRef]

59. Arroyo-Manzanares, N.; Huertas-Pérez, J.F.; García-Campaña, A.M.; Gámiz-Gracia, L. Simple methodology for the determination of mycotoxins in pseudocereals, spelt and rice. Food Control 2014, 36, 94-101. [CrossRef]

(C) 2020 by the authors. Licensee MDPI, Basel, Switzerland. This article is an open access article distributed under the terms and conditions of the Creative Commons Attribution (CC BY) license (http://creativecommons.org/licenses/by/4.0/). 